NBER WORKING PAPER SERIES

IS EVERYTHING NEUTRAL?

B. Douglas Bernheim

Kyle Bagwell

Working Paper No. 2086

NATIONAL BUREAU OF ECONOMIC RESEARCH

1050 Massachusetts Avenue

Cambridge, MA 02138

December 1986

We are indebted to Lawrence Summers for helpful discussions, as well as to participants at the various seminar presentations of this paper. This research was supported by the National Science Foundation, through Grant No. SES-8404164. The research reported here is part of the NBER's research program in Taxation. Any opinions expressed are those of the authors and not those of the National Bureau of Economic Research. 
NBER Working Paper \#2086

December 1986

Is Everything Neutral?

\section{ABSTRACT}

In his well-known analysis of the national debt, Robert Barro introduced the notion of a "dynastic family." This notion has since become a standard research tool, particularly in the areas of public finance and macroeconomics. In this paper, we critique the assumptions upon which the dynastic model is predicated, and argue that this framework is not a suitable abstraction in contexts where the objective is to analyze the effects of public policies. We reach this conclusion by formally considering a world in which each generation consists of a large number of distinct individuals, as opposed to one representative individual. We point out that family linkages form complex networks, in which each individual may belong to many dynastic groupings. The resulting proliferation of linkages between families gives rise to a host of neutrality results, including the irrelevance of all public redistributions, distortionary taxes, and prices. Since these results are not at all descriptive of the real world, we conclude that, in some fundamental sense, the world is not even approximately dynastic. These observations call into question all policy related results based on the dynastic framework, including the Ricardian equivalence hypothesis.

B. Douglas Bernheim Department of Economics Stanford University 404 Encina Hall Stanford, CA 94305 (415) $723-9678$
Kyle Bagwell

Department of Economics Northwestern University Evanston, Illinois 60201 


\section{Introduction}

Over the last decade, there has been a growing awareness that many important public policy issues turn critically upon the assumed nature of economic relationships within the family. This awareness is largely attributable to seminal papers by Robert Barro [1974] and Gary Becker [1974]. Barro's paper ostensibly concerns the national debt, but its implications are much more far-reaching. Specifically, Barro supplemented the traditional overlapping generations model with intergenerational altriusm, and argued, in essence, that voluntary transfers between parents and children cause the representative "dynastic" family to behave as though it is a single, infinite-lived individual. Policies which fail to affect the family's real opportunities are neutralized through private actions; thus, Ricardian equivalence and related propositions (concerning the irrelevance of government debt and Social Security) follow directly. The dynastic family model has since become a standard research tool, particularly in the areas of public finance and macroeconomics (see, for example, Abel [1984], Chamley [1981], and Judd [1985]). No doubt, its popularity in part reflects considerations of analytic convenience.1/

In this paper, we critique the dynastic family as a modelling tool, and argue that it is not a suitable abstraction in contexts where the objective is to analyze the effects of various public policies. Our criticism differs fundamentally from those offered by previous commentators (see e.g., Feldstein [1976], Buchanan [1976], and Tobin and Buiter [1980]), in that we assail neither the logic, nor the assumptions 
employed by studies which invoke the dynastic framework. Rather, we take these at face value, and show that the-- lead to untenable conclusions.

We reach these conclusions by formally considering a world in which each generation consists of a large number of distinct individuals, as opposed to one representative individual. While the notion of a representative consumer is always somewhat objectionable, here it is especially pernicious, in that it obscures considerations arising from the biological structure of families. For the human species, propogation requires the participation of two traditionally unrelated individuals. Thus, family linkages form complex networks, in which each individual may belong to many dynastic groupings. In this paper, we argue that the resulting proliferation of linkages between families gives rise to incomparably stronger neutrality properties under weaker conditions than those imposed by Barro. In particular, no government transfer (including those between unrelated members of the same generation) has any real effect, and all tax instruments (including so-called "distortionary" taxes) are equivalent to lump-sum taxes. In essense, the government can effect the allocation of real resources only by altering real expenditures. The efficiency role of government is thus severely limited, and the distributional role is entirely eliminated. More generally, we argue that if all linkages between parents and children are truly operative, then market prices play no role in the resource allocation process--the distribution of all goods is determined by the nature of intergenerational altruism. 
If taken literally, these results would have profound implications for the study of economics. We hardly intend to suggest that such extreme conclusions are warranted. Rather, when results stretch the bounds of credibility past the breaking point, it is natural to question the validity of underlying assumptions. We must therefore emphasize that we have obtained these results under relatively weak conditions, and that these same conditions are the fundamental building blocks of the dynastic model. Thus, refusal to accept the practical implications of our results is tantamount to a rejection of the dynastic framework, and calls into serious question the results (such as Ricardian equivalence) which follow from it.

In particular, we assume: (1) parents are operatively linked through transfers (gifts and bequests) with their children (although we do not specify the direction of these transfers), and (2) levels of gifts and bequests do not matter per se (consumers care only about the consequences of giving, and not the act of giving). If we are unwilling to accept the extreme implications described above, we must abandon one of these assumptions. Further analyses of economic policies, such as the effects of government debt, require us to specify quite explicitly which of these assumptions fails, and how it fails.

The paper is organized as follows. Initially, we assume the existence of pervasive linkages, and analyze their effects. In Section 2, we consider some simple examples which illustrate the principles driving our neutrality theorems. Analysis of our general model appears in Section 3. In Section 4, we argue that operative 
transfers between parents and their children are alone sufficient to establish pervasive linkages throughout the population. In Section 5, we clarify the nature of our results, reexamine the central assumptions, and consider various interpretations.
\end{abstract}

\title{
2. Examples
}

The linear structure of "dynastic" families in Barro [1974] allows him to model a family as, essentially, a single, infinite-lived consumer with dynamically consistent preferences. In particular, he specifies the well-being of generation $t$ as a function of t's own consumption, and the utility of t's immediate successor:

$$
u_{t}\left(c_{t}, u_{t+1}\right)
$$

Popular intuitive explanations of Ricardian equivalence are closely tied to this formulation: since the dynastic family chooses an optimal program, it will simply offset any exogenous, intertemporal redistributions of resources which might displace it from the optimum 2 / Once one recognizes the complex biological structure of families, this linearity disappears (for example, unrelated individuals share common descendents). Due to the existence of linkages between families, it is, in general, impossible to represent any particular family (or set of families) as a single, utility-maximizing agent, even when the wellbeing of each individual is assumed to depend only on his own consumption and the well-being of his children, as above. $3 /$ 
This observation raises an important question: does Barro's version of Ricardian equivalence depend upon the assumption that we can represent each family as a single infinite-lived consumer, or upon the more basic assumption that family members are linked through operative transfers? Our analysis demonstrates that the first of these assumptions is, in fact, unnecessary; however, this observation leads us to conclude that voluntary transfers through operative linkages are, under very weak assumptions, capable of neutralizing the effects of all tax and transfer policies (including so-called "distortionary" policies which are conditioned on behavior). Given the proliferation of linkages between families, the implications of these observations are profound. We defer our analysis of interfamily linkages to section 4 , and our discussion of larger implications to section 5 . In this and the following section, we simply assume that a number of individuals are linked through operative transfers, and explore the role of transfers in offsetting government policies. We begin with two simple examples.

Example 1: Suppose there are three individuals, 1, 2, and 3. Individuals 1 and 2 have quasiconcave preferences of the form

$$
u_{i}\left(c_{i}, c_{3}\right), i=1,2,
$$

while 3's preferences are simply $u_{3}\left(c_{3}\right)$. We may think of 3 as a common descendent of 1 and 2, who are unrelated. Each consumer $i$ is endowed with wealth $w_{i} \cdot 1$ and 2 divide this wealth between own consumption $c_{i}$, and a non-negative transfer to $3, b_{i}, i=1,2.3$ consumes $w_{3}+b_{1}+b_{2}$. 
There are, of course, a variety of ways in which 1 and 2 might determine the magnitude of their transfers to 3 . For the purpose of this illustration, we will assume that the exogenous environment is such that 1 and 2 must make simultaneous, non-cooperative choices. Accordingly, it is perhaps most natural to consider Nash equilibria in transfers to 3 . Suppose that there exists a Nash equilibrium in which 1 and 2 both make positive transfers. The reader may easily verify through a direct argument that private transfers will then neutralize the effects of all sufficiently small lump sum redistributional policies, 4/ despite the fact that this extended family does not act as a single, utility maximizing individual. 5/ Throughout this paper, we use a more powerful but less direct line of argument, which works as follows. We have described an environment in which two agents, 1 and 2, play a simple game. Each agent chooses an action (transfer) $b_{i}$ subject to the constraint $b_{i} \geqq 0$, and receives a payoff of

$$
u_{i}\left(w_{i}-b_{i}, w_{3}+b_{i}+b_{j}\right)
$$

By transferring $\mathbf{z}$ from 1 to 2 , the government alters this game as follows. Each agent still chooses an action $b_{i}$ subject to the constraint $b_{i} \geqq 0$, but receives different payoffs:

$$
\begin{aligned}
& u_{1}\left(w_{1}-z-b_{1}, w_{3}+b_{1}+b_{2}\right) \\
& u_{2}\left(w_{2}+z-b_{2}, w_{3}+b_{1}+b_{2}\right)
\end{aligned}
$$

Now we introduce the following change of variables: $\beta_{1}=b_{1}+z$, 
and $\beta_{2}=b_{2}-z$. That is, we think of agent 1 (2) as choosing $\beta_{1}\left(\beta_{2}\right)$ subject to the constraint $\beta_{1} \geqq z\left(\beta_{2} \geq z\right)$, and receiving payoffs

$$
u_{i}\left(w_{i}-\beta_{i}, w_{3}+\beta_{i}+\beta_{j}\right)
$$

Note that this differs from the original game in only two respects. First, the same abstract action has a different practical interpretation in each case. For example, we associate the choice " $b_{1}=5$ " with the interpretive label "1 transfers $\$ 5$ to $3, "$ while we associate $" \beta_{1}=5 "$ with the label "1 transfers $\$ 5-z$ to $3 . "$ Since all standard solution concepts have the property that strategically equivalent $6 /$ games give rise to equivalent sets of equilibria, changing the interpretations of abstract actions is inconsequential. 7/ Second, agents' opportunity sets differ between the two games. Since this difference is potentially substantive, we conclude that private actions neutralize the effects of government transfer policies as long as the original equilibrium is insensitive to perturbations in the agents' constraints.

This simple condition is, in principle, easily verifiable. Suppose, for example, that we have an initial Nash equilibrium with $\hat{b}_{i}>0, i=1,2$. Under the assumption that utility is quasiconcave, equilibrium behavior is insensitive to small perturbations of the constraints, so neutrality follows as an immediate corollary. However, it should now also be clear that quasiconcavity does not play a significant role in establishing this result. As long as $u_{i}$ is 
continuous and $i$ strictly prefers $\hat{b}_{i}$ to 0 , the basic robustness condition is satisfied. Since indifference between $\hat{b}_{i}$ and 0 is an extremely unlikely outcome (formally, one can show that it is a measure zero event in the space of potential preferences), the existence of an equilibrium with positive transfers is generally sufficient to guarantee that private actions will neutralize sufficiently small government transfer policies.

This alternative line of reasoning also allows us to conclude that neutrality will hold for a wide range of solution concepts. When an environment gives rise to a multiplicity of Nash equilibria, one often hopes to identify a unique outcome, or at least narrow down the set of possible outcomes, by employing some refinement of the Nash concept. As long as an interior Nash equilibrium strictly satisfies (violates) certain refined criteria, small perturbations of the corner constraints will not generally cause it to violate (satisfy) these criteria. 8 / More generally, it is natural to expect that interior equilibria will typically satisfy the basic condition unless the comer constraints play a special role in defining the relevant solution concept. Suppose for example that $x$ and $y$ can form binding contracts, so that transfers are determined through bargaining. If the relevant threat point is $b_{1}=b_{2}=0$, then the Nash bargaining solution will not give rise to neutralizing behavior. However, if a breakdown in negotiations is followed by non-cooperative behavior (so that a non-cooperative Nash equilibrium prevails), and if this threat point entails positive transfers, then the basic condition will generally hold, and private 
actions will neutralize small transfer policies.

While it would be interesting to identify more primitive exogenous conditions under which transfers are positive and equilibria are robust with respect to perturbations of corner constraints, this is not our current objective. As we argue in the next section, the most important aspects of dynastic behavior arise only when these hypotheses are satisfied. Since our objective is to critique the dynastic model by taking its central premises (which concern the endogenous properties of equilibria) at face value, it is appropriate to restrict our attention accordingly.

Example 2: Suppose everything is as in example 1, except that individual 1 chooses labor supply $\left(l_{1}\right)$ prior to the choices of consumption and transfers. Further assume that his utility is given by

$$
u_{1}\left(c_{1}, c_{3}, l_{1}\right)
$$

and that his wealth is

$$
w_{1}=w_{1}^{0}+w_{1}-z\left(l_{1}\right),
$$

where $w_{1}^{0}$ is non-labor income, $w$ is the wage rate, and $z$ is a tax schedule, used for redistributing wealth from 1 to 2 . Thus, 2 's wealth is

$$
w_{2}=w_{2}^{0}+z\left(l_{1}\right)
$$


The extensive form of this game is represented schematically in Figure 1(a). First, 1 chooses his labor supply; then, 1 and 2 play a simultaneous move "transfer game," as in example 1. Thus, if 1 chooses labor supply $\ell_{1}^{1}, 1$ and 2 play a transfer game in which their endowments are $w_{1}^{0}+w l_{1}^{1}-z\left(l_{1}^{1}\right)$, and $w_{2}^{0}+z\left(l_{1}^{1}\right)$, respectively (this game is denote " $\left.G_{1} "\right)$. Similarly, if 1 chooses labor supply $\ell_{1}^{2}, 1$ and 2 play the corresponding transfer game, $G_{2}$.

Suppose that the government contemplates an arbitrary change in the tax-transfer schedule from $z$ to $z^{\prime}$. At first, this may appear to alter the game in a fundamental way. For instance, when 1 chooses $\ell_{1}^{1}$, this induces a simultaneous move transfer game between 1 and 2 , where endowments are now $w_{1}^{0}+w l_{1}^{1}-z^{\prime}\left(l_{1}^{1}\right)$, and $w_{2}^{0}+z^{*}\left(l_{1}^{1}\right)$, respectively (this game is denoted $G_{1}^{\prime}$ in Figure $1(b)$ ). Yet the total resources of 1 and 2 are identical in $G_{1}$ and $G_{1}^{\prime}$. Thus, by the argument given in example 1, if we appropriately perturb the corner constraints in $G_{1}$, we obtain a game that is strategically equivalent to $G_{1}^{\prime}$. Clearly, this same reasoning applies regardless of 1 's labor supply decision (for instance, an appropriate perturbation in the corner constraints of $G_{2}$ yields a game that is strategically equivalent to $\left.G_{2}^{\prime}\right)$. Consequently, the only substantive difference between these two environments consists of perturbations in corner constraints. If the original equilibria (or set of equilibria) is robust with respect to such perturbations, then private actions will offset sufficiently small policy changes. 
Again, we would like to identify circumstances under which this robustness condition is likely to hold. For purposes of illustration, we consider subgame perfect Nash equilibria (see Selten [1965, 1975]). This solution concept demands that agents act in their own best interests at all times, and serves to rule out threats which are not credible, in the sense that agents would not be willing to carry them out. Formally, a Nash equilibrium is subgame perfect if strategies form Nash equilibria in every proper subgame. In the current context, this implies that every choice of $\ell_{1}$ must be followed by Nash behavior in the ensuing simultaneous more transfer game. Our discussion in example 1 establishes that, as long as the initial equilibrium entails positive transfers in some particular subgame, perturbations of the corner constraints will not generally alter behavior in that subgame. If this condition holds for every subgame, then the original set of perfect equilibria will indeed be robust with respect to arbitrary perturbations of the corner constraints.

The assumption that transfers are positive for every choice of $\ell_{1}$ is, of course, quite strong. However, the basic result typically holds as long as transfers are positive following any choice in some neighborhood of the original equilibrium selection, $\hat{l}_{1}$. By the preceding argument, policy changes will not alter the consequences of $i$ 's choices in this neighborhood--hence, $\hat{l}_{1}$ remains a local optimum. Furthermore, if 1 strictly prefers $\hat{l}_{1}$ to alternatives outside of this neighborhood, and if equilibrium outcomes following such alternatives vary continuously with the values of corner constraints, 
then $\hat{l}_{1}$ remains a global optimum for sufficiently small perturbations. This last condition (continuity) is relatively weak, and, for example, follows from quasiconcavity of $u_{i}$. It is interesting to contrast these results with those that follow from use of the unrefined Nash concept. There is typically a continuum of Nash equilibria for the game described here, which we construct as follows. If 1 selects some $\ell_{1}^{0}, 1$ and 2 play Nash choices in the ensuing subgame. For any other choice of $\ell_{1}, 2$ subsequently plays $b_{2}=0$ (1's choices in these subgames are irrelevant). Effectively, 2 induces 1 to choose $l_{1}^{0}$ by threatening to hurt 3 unless 1 complies.9/ Clearly, 2's ability to punish 1 though 3 determines the set of labor supply choices which are sustainable in some equilibrium. Any transfer from 1 to 2 strengthens this ability, and therefore expands the range of potential outcomes. There is then no guarantee that private actions neutralize redistributional policies; indeed, if 2 can select a threat, redistributions ordinarily have real effects. It is, however, important to reiterate that in such circumstances, the central properties of dynastic behavior are also lost (see Section 3B). The irrelevance of an apparently distortionary tax may, at first, seem counterintuitive--indeed, readers who are unfamiliar with abstract game theoretic arguments may wish to verify this result directly through standard comparative statics.10/ The imposition of a tax schedule certainly appears to change the relative price of $1^{\prime}$ 's leisure; should this not effect his decision? The fundamental insight here is that the price of 1 's leisure is not simply $w$, since he must also consider the 
effect of his labor-leisure choice on $2^{\prime} \mathrm{s}$ transfer to 3 . Thus, he faces some "shadow" wage, and it is this shadow wage which is invariant with respect to tax policy.

This invariance is easiest to understand in a single consumer world. As long as the government must balance its budget, no tax can distort behavior, since the individual knows that all revenues must be returned to him at some point. By way of contrast, in a representative consumer world each consumer is thought of as small relative to the economy, so that the fraction of marginal revenues distributed to any one consumer is negligible, and (in the absence of altruistic linkages) can be ignored. The point of our analysis is that, as long as consumers are linked through operative transfers, all marginal revenues associated with the taxation of a particular individual are, regardless of population size, eventually returned to that same individual, just as in a single consumer world.

Once we have established that private actions offset the effects of apparently distortionary taxes, it appears to follow immediately that prices must be locally indeterminant, and that sufficiently small changes in prices will have no effect on the allocation of real resources. For suppose that 1 and 2 are engaged in a market transaction; one might, for example, generalize our simple model by specifying that 2 is 1 's employer. Decreasing the price at which 2 buys labor from 1 seems analytically equivalent to imposing a linear tax on $1^{\text {'s }}$ earnings, and distributing the proceeds to 2 . While this intuition is essentially correct, its formalization raises 
some subtle issues which we address in Section 3D.

\section{General Analysis}

In the current section, we extend the analysis of Section 2 to more general contexts. Part A exhibits an overlapping generations model with intergenerational altruism. Part $B$ concerns the technical definition of operative links. We present the generalized neutrality results in part $C$, and discuss extensions in part $D$.

\section{A. The Model}

We consider a discrete time, $(t=1,2, \ldots)$ infinite horizon overlapping generations model. For simplicity, we assume that there is one composite good, which can either be consumed or invested. Current output is determined through a constant returns-to-scale production technology, as a function of current labor inputs and investment from the previous period. Markets are perfectly competitive; fims earn zero profits, and pay factor inputs their marginal products. Labor and capital are each homogenous, so that in period $t$ all labor receives a wage rate of $w_{t}$, and capital yields a gross return of $\alpha_{t}$, paid in period $t+1$ (the interest rate is equal to $\alpha_{t}-1$ ). We define

$$
\alpha^{t}=\prod_{\tau=1}^{t-1} \alpha_{t}
$$

Let $I_{t}$ be the set of individuals born in period $t$. We suppose that every individual lives for $M+1$ periods. Thus, $I^{t}$, the set of individuals living at time $t$, is given by 


$$
I^{t}=\bigcup_{k=0}^{M} I_{t-k}
$$

We will use $N_{t}$ and $N^{t}$ to denote the number of individuals in $I_{t}$ and $I^{t}$, respectively.

At time $t$, each individual $i \varepsilon I^{t}$ chooses consumption $\left(c_{i}^{t}\right)$, labor supply $\left(l_{i}^{t}\right)$, transfers to other living individuals $\left(b_{i j}^{t}, j \varepsilon I-\{i\}\right), 11 /$ purchases of physical capital $\left(s_{i}^{t}\right)$, and purchases of short term (single period) bonds $\left(d_{i}^{t}\right)$. Since our model abstracts from uncertainty, we will assume that bonds pay the competitive rate of return, $\alpha_{t}$.

Throughout our analysis, we employ the following notation. Let $b_{i}^{t}$ denote the vector of $i$ 's transfers in period $t$ :

$$
b_{i}^{t} \equiv\left(b_{i j}^{t}\right)_{j \varepsilon I-\{i\}}
$$

We will use $B^{t}$ to indicate the sequence of all transfer choices up to period $t-1$ :

$$
B^{t} \equiv\left(\left(b_{i}^{1}\right)_{i \varepsilon I}, \ldots,\left(b_{i}^{t-1}\right)_{i \varepsilon I}^{t-1}\right)
$$

(similarly for $C^{t}, L^{t}, S^{t}$, and $D^{t}$ ). We define a t-history of the economy as a complete record of all choices made through the end of period $t-1$ :

$$
H^{t}=\left(C^{t}, L^{t}, B^{t}, S^{t}, D^{t}\right)
$$

The government participates in this economy by financing a stream of real expenditures through tax levies and bond sales. Throughout, we 
assume that the stream of real expenditues $\left(g_{t}, t \geq 1\right)$ is fixed, and focus on the effects of alternative financial policies. We allow the government to specify period $t$ taxes on individual $i$ as an arbitrary function, $z_{i}^{t}\left(H^{t}\right)$, of the observed t-history. 12/ Note that this very general specification subsumes taxes on labor income, capital income, and transfers. It also allows for idiosyncratic provisions, such as income averaging. The government may also condition one individual's taxes on another's actions. In short, virtually any action may be taxed, and the corresponding rate schedule may be chosen without restriction.

Given a tax policy and real expenditure stream, the government balances its budget by issuing debt. Specifically, the supply of government bonds evolves as follows:

$$
d^{t}\left(H^{t}\right)+\sum_{i \in I} z_{i}^{t}\left(H^{t}\right)=\alpha_{t-1} d^{t}\left(H^{t-1}\right)+g_{t}
$$

For arbitrary taxes and expenditures, the implied deficit profile may, of course, be infeasible (i.e., debt might eventually exceed economic resources). We implicitly exclude such policies from consideration.

Prevailing prices and government financial policy determine the opportunity constraint of each consumer. Specifically, for each i $\varepsilon I^{t}$,

$$
\begin{aligned}
& c_{i}^{t}+s_{i}^{t}+d_{i}^{t}+\sum_{j \in I^{t}-\{i\}} b_{i j}^{t} \\
& =w_{t} l_{i}^{t}+\alpha_{t-1}\left(s_{i}^{t-1}+d_{i}^{t-1}\right)+\sum_{j \varepsilon I}^{t}-\{i\} \\
& b_{j i}^{t} .
\end{aligned}
$$


In addition, $i$ confronts a number of feasibility constraints:

$$
\begin{aligned}
0 & \leqq e_{i}^{t} \\
0 & \leqq s_{i}^{t} \\
\underline{b}_{i j}^{t}\left(H^{t}\right) & \leqq b_{i j}^{t} .
\end{aligned}
$$

Two comments are in order. First, we do not impose any constraints on i's purchases of bonds. In particular, it is possible to have $d_{i}^{t}<0$, which signifies that $i$ borrows at the competiive rate, $\alpha_{t}$. Thus, we have implicitly assumed that capital markets are perfect. It is straightforwara to relax this assumption by artificially limiting borrowing; as long as liquidity constraints are generally nonbinding, our central results continue to hold. Since the absence of binding liquidity constraints is fundamental to the dynastic formulation, it is appropriate for us to focus our attention on this case.

Second, we allow the lower bounds on i's period $t$ transfers, $b_{-j}^{t}\left(H^{t}\right)$, to depend upon the evolution of prior decisions, $\mathrm{H}^{\mathrm{t}}$. Ordinarily, we would expect these lower bounds to be invariant with respect to $\mathrm{H}^{\mathrm{t}}$ (generally, they equal zero). The more general formulation adopted here allows us to contemplate a wider class of perturbations to the corner constraints, and, correspondingly, a wider class of alternative financial policies.

We complete the model by assuming that it is possible to represent the preferences of each consumer $i$ by a utility function defined over 
choices of consumption and labor:

$$
u_{i}\left(C^{\infty}, L^{\infty}\right)
$$

Since we allow for dependence on the entire history of choices, this specification is extremely general. By imposing additional restrictions, one can obtain various formulations employed by other authors, such as Barro's [1974] dynastic specification. Note also that we do not require the utility of each individual to vary with the choices of all other individuals; indeed, $u_{i}$ would ordinarily be insensitive to changes in most of its potential arguments. We do, however, explicitly rule out direct dependence of preferences on the levels of transfers. This restriction is, of course, essential. As in the preceding section, our central result will depend upon a hypothesis about the sensitivity of equilibria to perturbations in the corner constraint. Since we generally expect interior equilibria to satisfy this hypothesis under a wide range of solution concepts, and since the hypothesis is in principle verifiable in any particular context, we wish to avoid tying our analysis directly to a particular notion of equilibrium. Thus, we will describe behavior within this economy in as general terms as possible. We assume that consumers take the wage rates and interest rates as fixed. A given profile of factor prices induces a game, where in each period $t$, consumers choose consumptions, labor supplies, transfers, purchases of capital, and purchases of bonds. Each distinct t-history $\mathrm{H}^{\mathrm{t}}$ identifies a distinct subgame originating in period t. Players may condition their period 
$t$ choices upon the actual t-history which has resulted from previous play. Thus, strategies consist of functions mapping t-histories to current choices.

Individuals are, of course, constrained to select strategies which satisfy their opportunity constraints in each period $t$ for all feasible t-histories and concurrent choices made by their contemporaries. This requirement is more demanding than it might at first appear. In particular, individual $i$ cannot simply specify $c_{i}^{t}, l_{i}^{t}$, $\left(b_{i j}^{t}\right)_{j \in I^{t}-\{i\}}, s_{i}^{t}$, and $d_{i}^{t}$ as functions of $H^{t}$ subject to budget balance, since concurrent deviations by contemporaries (e.g., a change of $b_{j i}^{t}$ for some $j$ ) might render these choices infeasible. Rather, he must allow one of these variables to be determined as a residual. As long as we confine our attention to pure strategy equilibria, i has no basis for preferring one residual variable to another (he always assumes that other players will select their equilbrium choices). For the purposes of our analysis, it is convenient to assume that consumption is always the residual variable. While selecting some other variable might well alter the specific set of equilibrium outcomes (since this changes the consequences of deviating from equilibrium actions for the deviating player), it would not affect our central arguments.

For any particular solution concept, there is a (potentially empty) set of equilibria among consumers for the game induced by each profile of possible factor prices. We will say that a particular price profile is a full equilibrium if there exists an equilibrium among consumers relative to these prices such that along the equilibrium path, 
(i) consumers demand in aggregate the amount of bonds supplied by the government, and ( $i i)$ the aggregte demand for capital (labor) equals the aggregate supply of capital (labor). Condition (ii) holds as long as full employment of factor supplies generates marginal products equal to the assumed factors prices.

\section{B. Operative Linkages}

Barro's [1974] formulation of the dynastic family employs both a restrictive specification of preferences and a restrictive notion of equilibrium (see footnote 1). In addition, he assumes that successive generations are operatively linked, in the sense that parents make positive, discretionary transfers to their children. Within his framework, this condition is sufficient to guarantee that equilibrium behavior is insensitive to perturbations in the lower bounds which constrain specific transfer decisions. We have already remarked that this implication does not necessarily hold in other more general contexts. Indeed, for all but the simplest models (such as our examples), it is extremely difficult to derive exogenous conditions which guarantee the irrelevance of perturbing apparently non-binding transfer constraints.

One might initially suspect that, as in Section 2, the desired implication would follow directly from appropriate convexity conditions. Unfortunately, when the preferences of successive generations conflict, convexity of an individual's decision problem depends not only upon the characteristics of utility functions and budget constraints, but also upon the properties of equilibrium 
strategies. In general, it is extremely difficult to guarantee that these strategies are well-behaved.13/ Furthermore, in various kinds of non-cooperative equilibria, one individual may condition his transfer upon another's behavior in order to exert influence. If the first individual can credibly threaten to sever financial ties, then the location of his corner constraint will affect behavior even if one observes positive discretionary transfers in equilibrium (Bernheim, Shleifer, and Summers [1985] develop this line of argument in greater detail). Once again, it is very difficult to rule out this possibility by imposing restrictions either on the exogenous environment or on the notion of equilibrium.

Rather than search for a set of exogenous conditions which would guarantee the irrelevance of apparently non-binding corner constraints, our strategy is to assume directly that perturbations of certain constraints have no effect on equilibrium behavior. Formally, we proceed as follows. A potential link is a triplet, $(i, j, t)$, such that $i \neq j$, and $i, j \in I^{t}$ (since $i$ and $j$ are both alive in period $t$, it is conceivable that $i$ could transfer resources to $j$ at that time). Let $\Lambda$ be the set of all potential links. Consider some $\lambda \subset \Lambda$, and choose some vector of real numbers $\varepsilon=\left(\varepsilon_{i j}^{t}\right)(i, j, t) \varepsilon \lambda$. The vector of functions $\left(\underline{\beta}_{i j}^{t}\right)(i, j, t) \varepsilon \lambda$ is an $\varepsilon$-perturbation of the original constraints $\left(\underline{b}_{-i j}^{t}\right)(i, j, t) \varepsilon \lambda$ if for all $(i, j, t) \varepsilon \lambda$ and $H^{t}$,

$$
\left|\underline{\beta}_{i j}^{t}\left(H^{t}\right)\right|<\varepsilon_{i j}^{t}
$$

Subsequent to some perturbation, the constraints become 


$$
b_{i j}^{t} \geq b_{i j}^{t}\left(H^{t}\right)+\beta_{i j}^{t}\left(H^{t}\right)
$$

for all $H^{t}$ and $(i, j, t) \varepsilon \lambda$. We will say that $\lambda \subset \Lambda$ is a set of jointly operative links if there exists some $\varepsilon>0$ such that no $\varepsilon$-perturbation of $\left(\underline{b}_{i j}^{t}\right)(i, j, t) \varepsilon \lambda$ alters the set of equilibria in the game induced by the prevailing profile of factor prices.

In the following section, we assume that particular links are jointly operative. Unfortunately, this assumption concerns the endogenous properties of equilbrium; its validity is therefore highly dependent both upon the environment considered, and upon the notion of equilbrium employed. Certainly, assumptions of this kind are less satisfactory from a theoretical point of view than those that concern exogenous characteristics of the model. However, the reader should recall that, in formulating the dynastic model, Barro [1974] assumes that transfers are positive; this too concerns a property of equilibrium. Since our objective is to critique the dynastic family as an analytic tool by taking its basic premises at face value, the only relevant question is whether we have assumed more than Barro.

We have already remarked that Barro's assumption is equivalent to ours within the context of his model. More generally, the important features of dynastic behavior do not necessarily follow from the assumption that transfers are positive, unless our stronger assumption (the irrelevance of perturbing corner constraints) is also satisfied. One must therefore invoke this assumption (or more primitive conditions 
which guarantee it) when generalizing the dynastic model to more complex environments.

We demonstrate this principle in a model which is only slightly more general than Barro's. Assume that $N_{t}=M_{t}=1$, individuals desire consumption only in the second period of life, labor supply is fixed, and $b_{t, t+1}^{t}=0$. This is essentially Barro's model, except that we allow for arbitrary forms of altruism. Our strategy is to impose dynasticism by assuming that $\lambda \equiv\{(t, t+1, t) \mid t \geqq 1\}$ is a set of jointly operative links, rather than by employing the weaker assumption that $b_{t, t+1}^{t}>0$ for all $t$. As we now show, failure of our assumption implies that one can always devise an arbitrarily small deficit policy that has real effects, even if transfers are positive in every period. Thus, one cannot establish Ricardian equivalence without employing our formulation of the operative transfer condition.

Assume that initially the government neither levies taxes nor issues debt. A particular profile of factor prices induces a game in which each successive generation chooses $b_{t, t+1}^{t}$ subject to the constraint $b_{t, t+1}^{t} \geqq 0$. Consumption evolves according to the equation

$$
c_{t}^{t}=w_{t}+\alpha_{t-1} b_{t-1, t}^{t-1}-b_{t, t+1}^{t}
$$

Suppose that the operative transfer condition is not satisfied. Then for any $\varepsilon=\left(\varepsilon^{1}, \varepsilon^{2}, \ldots\right)>0$ there exists an $\varepsilon$-perturbation, $\left(\underline{\beta}_{t, t+1}^{t}\right)_{t=1}^{\infty}$, of the transfer constraints such that this perturbation alters equilibrium behavior. For expositional simplicity, suppose that one can always find such a perturbation where each $\beta_{t, t+1}^{t}$ is invariant 
$-24-$

with respect to $\mathrm{H}^{\mathrm{t}}$. Subsequent to this perturbation, a particular profile of factor prices induces a game in which each successive generation chooses $b_{t, t+1}^{t}$ subject to the constraint $b_{t, t+1}^{t} \geqq \underline{\beta}_{t, t+1}^{t}$, and where consumption evolves as before. By assumption, this game gives rise to different behavior than does our original game.

Now we consider the following fiscal policy. The government levies taxes as follows:

$$
\begin{aligned}
& z_{1}^{1}=\underline{\beta}_{t, t+1}^{t} \\
& z_{t}^{t}=\underline{\beta}_{t, t+1}^{t}-\alpha_{t-1} \underline{\beta}_{t-1, t}^{t-1} .
\end{aligned}
$$

In addition, it balances its budget constraint year by year through issuing debt:

$$
d^{t}=-\underline{B}_{t, t+1}^{t}
$$

Suppose that this policy is neutral, ie., that its implementation does not alter capital accumulation or associated factor prices. The original factor prices induce a game in which each successive generation chooses $b_{t, t+1}^{t}$ subject to the original non-negativity constraint, and in which consumption evolves as follows:

$$
c_{t}=w_{t}^{t}-z_{t}^{t}+\alpha_{t-1} b_{t-1, t}^{t-1}-b_{t, t+1}^{t}
$$

Now we perform the following change of variables. For each $t$, let

$$
\beta_{t, t+1}^{t} \equiv b_{t, t+1}^{t}+\underline{\beta}_{t, t+1}^{t}
$$


Subsequent to implementation of the policy, we may think of consumers as choosing $\beta_{t, t+1}^{t}$ subject to the constraint that $\beta_{t, t+1}^{t} \geqq \underline{\beta}_{t, t+1}^{t}$. Consumption evolves as follows:

$$
\begin{aligned}
c_{t} & =w_{t}^{t}-z_{t}^{t}+\alpha_{t-1}\left(\beta_{t-1, t}^{t-1}-\underline{\beta}_{t-1, t}^{t-1}\right)-\left(\beta_{t, t+1}^{t}-\underline{\beta}_{t, t+1}^{t}\right) \\
& =w_{t}^{t}+\alpha_{t-1} \beta_{t-1, t}^{t-1}-\beta_{t, t+1}^{t} .
\end{aligned}
$$

Thus, the same numerical choices are feasible, and lead to the same consumption streams in the games induced by perturbing either the corner constraints or the policy. Since these two games are strategically equivalent, their equilibria must be identical. But then by hypothesis the policy perturbation must have a real effect on consumption. Since this alters aggregate capital accumulation and associated factor prices, we have a contradiction.

Of course, failure of the operative transfer condition does not guarantee that we can find an arbitrarily small perturbation of the corner constraints, $\left(\beta_{t, t+1}^{t}\right)_{t=1}^{\infty}$, that both alters equilibrium behavior and has the property that each $\underline{\beta}_{t, t+1}^{t}$ is invariant with respect to $\mathrm{H}^{t}$, as assumed above. However, this assumption seems relatively mild. Recall that each distinct t-history $\mathrm{H}^{\mathrm{t}}$ determines a different subgame. Ordinarily, perturbations fail to affect behavior because they do not change the outcome in any relevant subgame. Since each subgame has an independent existence, one should then be able to perturb the constraints differntly in different subgames, without effect (the reader may wish to refer back to example 2 for an illustration). Thus, when 
all sufficiently small perturbances satisfying the invariance condition fail to affect behavior, it is natural to expect that the operative transfer condition will generally hold. Even when this reasoning is invalid, one can show through a modification of our previous argument that failure of the operative transfer condition implies the existence of some arbitrarily small, non-neutral deficit policy in which the government adjusts its bond sales in response to choices of deceased generations.

We close our discussion of operative transfers with one final remark. While the issues raised in this section may appear purely technical, they raise an important empirical issue. Specifically, once one steps out of Barro's simple framework, it becomes difficult to determine whether or not any given consumer is up against a binding constraint, appropriately defined. Certainly, the observation of positive, discretionary transfers does not constitute sufficient evidence to establish that two individuals are operatively linked. This issue must be resolved through more subtle means (see, for example, the empirical analysis in Bernheim, Shleifer, and Summers [1985]).

\section{Results}

We begin our analysis of government fiscal policy by restricting attention to equilibria which satisfy a certain strong condition, which we designate the linkage hypothesis. Formally,

Linkage hypothesis: There exists a set of jointly operative links $\lambda$ and an integer $T$ such that for each $t \geqq 1$ the following 
property holds. For all $i, j \varepsilon I^{t}$, there exists a finite integer $p$ and sequences $\left(i_{1}, \ldots, i_{p}\right)$ and $\left(\tau_{1}, \ldots, \tau_{p-1}\right)$ with $i=1$, and $j=i_{p}$ such that for $k=1, \ldots, p-1, t \leqq \tau_{k} \leqq t+T$, and either $\left(i_{k}, i_{k+1}, \tau_{k}\right) \varepsilon \lambda$ or $\left(i_{k+1}, i_{k}, \tau_{k}\right) \varepsilon \lambda$.

Loosely, this hypothesis implies that in each period $t$, one can find a chain of operative linkages connecting any two living individuals, where each link consists of a transfer made sometime between periods $t$ and $t+T$. At first, this requirement might appear extremely demanding: indeed, Barro's dynastic model is based on the seemingly less restrictive assumption that parents are operatively linked to their children. However, as we show in Section 4, Barro's assumption virtually guarantees that the linkage hypothesis will be satisfied. By invoking this hypothesis, we therefore do nothing more than take the premises of the dynastic model at face value.

We now demonstrate that, when the linkage hypothesis is satisfied, sufficiently small but otherwise arbitrary perturbations of government fiscal policy are irrelevant. We define a policy perturbation as follows. Consider some vector of real numbers $\eta=\left(\eta^{1}, \eta_{0}^{1}, \eta^{2}, \eta_{0}^{2}, \ldots\right)$. $\left\langle\delta^{t},\left(\xi_{i}^{t}\right)_{i \varepsilon I^{t}}\right\rangle_{t=1}^{\infty}$ is an $n$-perturbation of some initial policy $\left\langle d^{t},\left(z_{i}^{t}\right)_{i \in I}\right\rangle_{t=1}^{\infty}$ if

$$
\begin{aligned}
& \left|\delta^{t}\left(H^{t}\right)\right|<\eta^{t} \\
& \left|\xi_{i}^{t}\left(H^{t}\right)\right|<\eta_{0}^{t}
\end{aligned}
$$


and

$$
\delta^{t}\left(H^{t}\right)+\sum_{i \varepsilon I} \xi_{i}^{t}\left(H^{t}\right)=\alpha_{t-1} \delta^{t-1}\left(H^{t-1}\right)
$$

for all $t$, $i \varepsilon I^{t}$, and t-histories $H^{t}$. Subsequent to the perturbation, the government's deficit and tax policies are given by

$$
d^{t}\left(H^{t}\right)+\delta^{t}\left(H^{t}\right)
$$

and

$$
z_{i}^{t}\left(H^{t}\right)+\xi_{i}^{t}\left(H^{t}\right)
$$

respectively.

Proposition: Suppose that some full equilibrium satisfies the linkage hypothesis. For some $\eta>0$ and every $\eta$-perturbation of the government's fiscal policy, there exists a full equilibrium in which factor prices, labor supplies, consumption decisions, and purchases of physical capital are all unaffected. In such an equilibrium, the policy perturbation simply induces offsetting private transfers and bond purchases.

We establish this proposition by showing that, subsequent to the policy perturbation, there must exist an equilibrium for the game induced by the original profile of factor prices in which consumers select the same levels of consumption and factor supplies as in the original full equilibrium, and in which the aggregate demand for 
government bonds changes to match supply in every period. The desired conclusion follows immediately.

We proceed by first considering three simple classes of policy perturbations, labelled $A, B$, and $C$. These provide the building blocks for analyzing more complex fiscal policies.

Class A: This class of perturbations consists of transfers between pairs of individuals who are directly linked. That is, we choose some $(i, j, t) \varepsilon I$, select $\xi_{i}^{t}$ arbitrarily, and set

$$
\xi_{j}^{t}\left(H^{t}\right)=-\xi_{i}^{t}\left(H^{t}\right)
$$

for all $\mathrm{H}^{t}$. All other aspects of fiscal policy remain unchanged. To demonstrate the irrelevance of this policy, we consider the following change of variables for i's transfer choice. For each history $\mathrm{H}^{\mathrm{t}}$, let

$$
\beta_{i j}^{t}\left(H^{t}\right)=b_{i j}^{t}+\xi_{i}^{t}\left(H^{t}\right)
$$

(that is, we adopt a different change of variables in each subgame). Clearly, the same numerical choices yield the same payoffs prior to the perturbation, and in the transformed game after the perturbation. However, subsequent to the perturbation, the transfer constraint becomes

$$
\beta_{i j}^{t}\left(H^{t}\right) \geqq b_{i j}^{t}\left(H^{t}\right)+\xi_{i}^{t}\left(H^{t}\right)
$$

This game is therefore strategically equivalent to one in which the perturbation 


$$
\underline{\beta}_{i j}^{t}\left(H^{t}\right) \equiv \xi_{i}^{t}\left(H^{t}\right)
$$

is applied to $b_{-i j}^{t}$. Since $i$ and $j$ are operatively linked, this perturbation of the corner constraint will not affect behavior as long as $\underline{\beta}_{i}^{t}$ is sufficiently small. But then the policy perturbation is also irrelevant, in the sense that it only alters i's transfer to $j$.

Class B: In this class of policy perturbations, the government issues debt, distributes the proceeds to some individual $i$, and retires the debt in the subsequent period by taxing the same individual. That is, we choose $i \varepsilon I^{t} \cap I^{t+1}$, select $\xi_{i}^{t}$ arbitrarily, and set

$$
\delta^{t}\left(H^{t}\right)=-\xi_{i}^{t}\left(H^{t}\right)
$$

and

$$
\xi_{i}^{t+1}\left(H^{t+1}\right)=-\alpha_{t} \xi_{i}^{t}\left(H^{t}\right)
$$

for all $\mathrm{H}^{\mathrm{t}}$. All other aspects of fiscal policy remain unchanged. To demonstrate the irrelevance of this policy, we consider the following change of variables for i's bond purchases. For each history $\mathrm{H}^{\mathrm{t}}$, let

$$
\sigma_{i}\left(H^{t}\right)=s_{i}^{t}-\delta^{t}\left(H^{t}\right)
$$

Clearly, the same numerical choices yield the same payoffs prior to the perturbation, and in the transformed game after the perturbation. Indeed, these two games are strategically equivalent, since there are no constraints on borrowing or lending. Equilibrium therefore entails the 
same numerical choices. This implies that $i$ simply increases his bond purchases by $\delta^{t}\left(H^{t}\right)$.

Class C: In this class of perturbations, we consider transfers between pairs of individuals who are alive at the same point in time. That is, we choose $i, j \varepsilon I^{t}$, select $\xi_{i}^{t}$ arbitrarily, and set

$$
\xi_{j}^{t}\left(H^{t}\right)=-\xi_{i}^{t}\left(H^{t}\right)
$$

for all $H^{t}$. All other aspects of fiscal policy remain unchanged. Let $i_{1}, \ldots, i_{p}$ be the sequence of individuals described in the linkage hypothesis. For each $k=1, \ldots, p-1$, define the following policy perturbations:

(1)

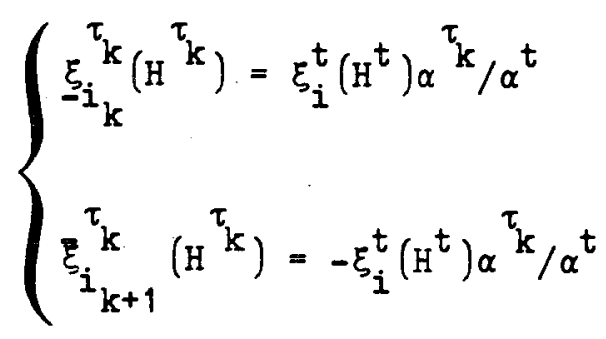

For $k=0, \ldots, p$, let

(2)

$$
\left\{\begin{array}{l}
\tilde{\xi}_{i_{k+1}^{\tau}}^{\tau_{k}}\left(H^{\tau}\right)=\xi_{i}^{t}\left(H^{t}\right) \alpha^{\tau} / \alpha^{t} \\
\tilde{\xi}_{i_{k+1}{ }^{\tau}{ }_{k+1}}\left({ }^{\tau}{ }^{\tau+1}\right)=-\xi_{i}^{t}\left(H^{t}\right) \alpha^{\tau_{k+1}} / \alpha^{t} \\
\delta_{k}^{\tau}\left(H^{\tau}\right)=\operatorname{sgn}\left(\tau_{k}-\tau_{k+1}\right) \xi_{i}^{t}\left(H^{t}\right) \alpha^{\tau} / \alpha^{t} \\
\text { for } \min \left(\tau_{k}, \tau_{k+1}\right) \leqq \tau<\max \left(\tau_{k}, \tau_{k+1}\right)
\end{array}\right.
$$


where $\tau_{0} \equiv \tau_{p+1} \equiv t$.

First, we note that the cumulative effect of all these component policies is equivalent to the effect of the original policy. In particular, the effect on $i_{k}$ in period $\tau_{k-1}$ is

$$
\bar{\xi}_{i_{k}}^{\tau_{k-1}}\left({ }^{\tau}{ }^{\tau}{ }^{-1}\right)+\tilde{\xi}_{i_{k}}^{\tau_{k-1}}\left(H{ }^{\tau}{ }^{\tau-1}\right)= \begin{cases}0 & k=2, \ldots, p \\ \xi_{i}^{t}\left(H^{t}\right) & k=1\end{cases}
$$

Similarly, the effect on $i_{k}$ in period $\tau_{k}$ is

$$
\left.\left.\underline{\xi}_{i_{k}}{ }^{\tau}{ }_{(H}{ }^{\tau}{ }^{\tau}\right)+\tilde{\xi}_{i_{k}{ }^{\tau}}{ }{ }^{\tau}{ }^{\tau} k\right)= \begin{cases}0 & k=1, \ldots, p-1 \\ -\xi_{i}{ }^{t}(H) & k=p\end{cases}
$$

Finally, the change in period $\tau$ bond issues is

$$
\begin{gathered}
\sum_{k=0}^{p} \delta_{k}^{\tau}\left(H^{\tau}\right)=\xi_{i}^{t}\left(H^{t}\right) \alpha^{\tau} / \alpha{ }_{k}^{t} \sum_{k+1} \leqq \tau<\tau_{k} \\
s g n\left(\tau_{k}-\tau_{k+1}\right) \\
=0
\end{gathered}
$$

since $\tau_{0}=\tau_{p+1}$.

Now note that for each $k,(1)$ is a Class A policy, and (2) is a Class B policy. We know that Class B policies are always irrelevant. We can therefore focus on the Class A policies. Reasoning as before, we see that adoption of all the Class A policies described in (1) yields a game that is equivalent to one which is induced by perturbing the 
original transfer constraints as follows: if $\left(i_{k}, i_{k+1}, \tau_{k}\right) \varepsilon L$,

$$
\underline{\beta}_{i_{k}, i_{k+1}{ }_{k}}\left(H^{{ }^{\tau} k}\right) \equiv \xi_{i}^{t}\left(H^{t}\right) \alpha^{\tau_{k} / \alpha}{ }^{t} \text {; }
$$

otherwise,

$$
\beta_{i_{k+1}{ }^{\tau}{ }_{i}}\left(H^{\tau}{ }^{\tau}\right) \equiv-\xi_{i}^{t}\left(H^{t}\right) \alpha^{\tau}{ }^{\tau} / \alpha^{t} .
$$

Since no link need appear twice in this chain, we can obviously make the composite perturbation to transfer constraints arbitrarily small by taking $\xi_{i}^{t}$ small. Since a small perturbation of transfer constraints has no effect on behavior, the corresponding policy perturbation must be irrelevant.

Having analyzed Cases A, B, and C, we are now prepared to consider an arbitrary policy perturbation, $\left\langle\delta^{t},\left(\xi_{i}^{t}\right)_{i \in I} t_{t=1}^{\infty}\right.$. We begin by decomposing this into component parts. For each $t$, we define $N^{t}-N_{t-M-1}$ policy perturbations as follows. For all i $\varepsilon I^{t}-I_{t-M}$ let

$$
\left\{\begin{array}{l}
\xi_{i}^{t}\left(H^{t}\right)=-\delta^{t}\left(H^{t}\right) /\left(N^{t}-N_{t-M}\right) \\
\xi_{i}^{t+1}\left(H^{t+1}\right)=\alpha_{t} \delta^{t}\left(H^{t}\right) /\left(N^{t}-N_{t-M}\right) \\
\tilde{\delta}_{i}^{t}\left(H^{t}\right)=\delta^{t}\left(H^{t}\right) /\left(N^{t}-N_{t-M}\right) .
\end{array}\right.
$$

Next, define $\mathrm{N}^{\mathrm{t}}-1$ policy perturbations as follows. Choose some $i * \varepsilon I_{t-M}$, and for all $i \varepsilon I^{t}-\left\{i^{*}\right\}$, let 
(4)

$$
\left\{\begin{array}{l}
\hat{\xi}_{i}^{t}\left(H^{t}\right)=\xi_{i}^{t}\left(H^{t}\right)-\xi_{i}^{t}\left(H^{t}\right)-\bar{\xi}_{i}^{t}\left(H^{t}\right) \\
\hat{\xi}_{i}^{t i}\left(H^{t}\right)=\xi_{i}^{t}\left(H^{t}\right)+\bar{\xi}_{i}^{t}\left(H^{t}\right)-\xi_{i}^{t}\left(H^{t}\right) .
\end{array}\right.
$$

We now establish that the cumulative effect of these component policies is equivalent to the effect of the original policy. The effect on debt at time $t$ is clearly

$$
\left(N^{t}-N_{t-M}\right) \delta^{t}\left(H^{t}\right) /\left(N^{t}-N_{t-M}\right)=\delta^{t}\left(H^{t}\right) .
$$

The effect on $i \in I^{t}-\left\{i^{*}\right\}$ is

$$
\hat{\xi}_{i}^{t}\left(H^{t}\right)+\underline{\xi}_{i}^{t}\left(H^{t}\right)+\bar{\xi}_{i}^{t}\left(H^{t}\right)=\xi_{i}^{t}\left(H^{t}\right) .
$$

Finally, the effect on $i^{*}$ is

$$
\begin{aligned}
\sum_{i \varepsilon I^{t}-\left\{i^{*}\right\}} \hat{\xi}_{i *}^{t i}\left(H^{t}\right) & =\sum_{i \varepsilon I^{t}-\left\{i^{*}\right\}}\left[\underline{\xi}_{i}^{t}\left(H^{t}\right)+\bar{\xi}_{i}^{t}\left(H^{t}\right)-\xi_{i}\left(H^{t}\right)\right] \\
& =-\delta^{t}\left(H^{t}\right)+\alpha_{t-1} \delta^{t-1}\left(H^{t-1}\right)-\sum_{i \varepsilon I^{t}-\left\{i^{*}\right\}} \xi_{i}^{t}\left(H^{t}\right) \\
& =\xi_{i *}^{t}\left(H^{t}\right),
\end{aligned}
$$

where the last equality follows from the government's budget constraint. Note that for each $i E I^{t}-I_{t-M},(3)$ is a Class B policy. Recall once again that Class B policies are completely irrelevant. We can therefore confine attention to the class $C$ policies described in (4). We know that each Class C policy induces a game which, after a 
change of variables, is equivalent to one in which we have perturbed corner constraints. Similarly, the entire policy induces a game which, after making all component changes in variables, is equivalent to one in which we have made all component perturbations in the appropriate corner constraints. We need only verify that the transformed game (i.e., the one in which variables have been changed) is well-defined, and that the corresponding aggregate perturbation to corner contraints can be made arbitrarily small by taking the policy to be small.

Fix some period $t$, and consider a link, $(i, j, t) \varepsilon L$. This link might appear in any chain connecting any two individuals living in periods $t-T$ through $t$. However, it does not appear in any other chain. The total number of potential appearances is therefore finite (specifically, it is bounded by $\sum_{\tau=T}^{t}\left(I^{\tau}-1\right)$ ). Consequently, the composite change of variables is well-defined. The corresponding total perturbation to the link $(i, j, t)$ is just equal to the sum of the component perturbations. We can clearly make this sum arbitrarily small by taking $\left(\eta^{t-T}, \eta_{0}^{t-T}, \ldots, \eta^{t}, \eta_{0}^{t}\right)$ sufficiently small. Now choose $\varepsilon$ such that no $\varepsilon$-perturbation to the corner constraints affects equilibrium behavior. Since there are a finite number of individuals living in period $t$, we can find some $\left(\hat{\eta}_{t}^{t-T}, \hat{\eta}_{0, t}^{t-T}, \ldots, \hat{\eta}_{t}^{t}, \hat{\eta}_{0, t}^{t}\right)>0$ such that for $\eta$ satisfying

$$
\left(\eta^{t-T}, \eta_{0}^{t-T}, \ldots, \eta^{t}, \eta_{0}^{t}\right) \leqq\left(\hat{\eta}_{t}^{t-T}, \hat{\eta}_{0, t}^{t-T}, \ldots, \hat{\eta}_{t}^{t}, \hat{\eta}_{0, t}^{t}\right)
$$

the aggregate perturbation to each $\underline{b}_{i j}^{t}, \underline{\beta}_{i j}^{t}$, implied by any $n$-perturbation of fiscal policy satisfies 


$$
\left|\beta_{i j}^{t}\left(H^{t}\right)\right|<\varepsilon_{i j}^{t}\left(H^{t}\right)
$$

for all $H^{t}$ and $i, j$ with $(i, j, t) \varepsilon L$. Thus, by choosing $\eta$ such that

$$
\begin{aligned}
\left(\eta^{t}, \eta_{0}^{t}\right) & =\left(\min \left\{\hat{\eta}_{t-T}^{t}, \cdots \hat{\eta}_{t}^{t}\right\}, \min \left\{\hat{\eta}_{0, t-T}^{t}, \ldots, \hat{\eta}_{0, t}^{t}\right\}\right) \\
& >0
\end{aligned}
$$

for all $t$, we guarantee that the aggregate perturbation to each $\underline{b}_{i j}^{t}, \underline{\beta}_{i j}^{t}$, implied by any $\eta$-perturbation of fiscal policy satisfies

$$
\left|\beta_{i j}^{t}\left(H^{t}\right)\right|<\varepsilon_{i j}^{t}\left(H^{t}\right)
$$

for all $H_{t}$ and $(i, j, t) \varepsilon L$. The proposition is therefore established.

One aspect of our proof deserves comment. Note that the number of potential perturbations to any particular link (which corresponds to the number of potential appearances of that link in chains connecting pairs of individuals) rises proportionately with the size of the population. To keep the potential composite perturbation small, it appears that we must therefore take each component perturbation smaller and smaller as the population grows. This observation suggests that, in large economies, only very tiny policy perturbations are irrelevant. We believe, however, that this conclusion is unwarranted. In the proof, we have fixed the population size, and calculated bounds conservatively by assuming that every potential appearance of a given link is an actual appearance. We could obtain tighter bounds by using only actual 
appearances, by choosing chains to avoid repeated appearances of any particular link, and by noting that many perturbations may be partly offsetting. Indeed, it is conceivable that the number of actual perturbations of any particular link may not rise with the population size (see Section 4).

This observation also raises a methodological issue. One can interpret our result as establishing that fiscal policies have real effects only when they cause non-negativity constraints to become relevant (ordinarily, by driving some individual to a corner). Whenever the dynastic model is employed, one assumes that the validity of the model's basic premises (including the assumption that particular links are operative) is robust with respect to an interesting range of environments (otherwise, the model may become inapplicable if the environment changes slightly). Government fiscal policy is certainly an aspect of the environment; indeed, the dynastic model is often used to compare the effects of alternative policies. If we take the premises of this framework at face value, we must therefore assume that certain nonbinding corner constraints play no role in determining the effects of a broad range of fiscal policies. Our analysis then establishes that these policies are irrelevant.

\section{Extensions and Qualifications}

In Section 2, we pointed out that changing a price is analogous to imposing a tax on one party to a transaction, and distributing the proceeds to the other party. We therefore claimed that, when consumers are linked through operative transfers, prices are indeterminant (at 
least locally), and price changes within the region of indeterminacy have no effect on the allocation of resources. While this argument may appear straightforward, it is not strictly correct within the context of the model considered here. Indeed, small changes in prices may well affect the resulting allocation of resources. However, this occurs only because consumers and firms exercise peculiar forms of myopia. In both cases, this myopia is disguised as assumptions about perfect competition.

Specifically, each consumer trades with the market, rather than with some set of other consumers. When he contemplates changing his purchases or sales, he does not realize that this must affect the purchases or sales of others. If he considers buying more (selling less), he assumes that the market supplies the incremental goods, and no one else is affected. Similarly, if he considers buying less (selling more), the market picks up the residual slack in demand.

Suppose instead that we formulate the process of competitive exchange as follows. Each consumer takes the market price as fixed, and announces demand for (supply of) each good. If aggregate supply exceeds aggregate demand, transactions are rationed to suppliers so that each supplier sells the same fraction of his announcement. If aggregate demand exceeds aggregate supply, transactions are rationed so that each purchaser buys the same fraction of his announcement. Equilibrium consists of a price and a set of announcements for which aggregate supply and demand are equal, and no one wishes to alter his announcement. 
Note that on this formulation, each agent believes that he can effectively buy and sell as much of each good as he likes at the going price. However, a supplier (similar statements hold for purchasers) rationally acknowledges that an increase in his sales must either increase total purchases comensurately (when purchasers are rationed), or must reduce sales by others commensurately (when suppliers are rationed). In either case, the impact of his action is divided evenly between either all purchasers or all suppliers, so that in large populations, the effect on any given individual is negligible. On this basis, one typically ignores these effects in competitive models, just as one ignores budget-balancing distributions of marginal tax revenues generated by a change in some individual's behavior. Analogously to our discussion of taxes, this leads one astray under the current set of assumptions, regardless of population size. For once we have paired buyers and sellers to form complete transactions, a change in price is indeed analytically equivalent to a tax levied on one party, and distributed to the other. Since adoption of this alternative framework does not alter our central result, $14 /$ both taxes and prices will be neutral.

The preceding argument applies directly only if both parties to a transaction are individuals. If one party is a firm, matters are more complex. Indeed, one might at first think that in this case, prices must matter. After all, unless prices are chosen to lie on the factor price frontier (see Diamond [1965]), constant returns-to-scale firms will either shut down, or attempt to produce infinite quantities of 
output. Yet this argument is misleading, since it presupposes that competitive firms will act as profit maximizing automata. Under our current set of assumptions, profit maximization is simply not a sensible objective. Firms ought to be creatures of their owners; they should attempt to earn profits only if this benefits their owners. A fall in the price of labor does indeed cause the firm to earn profits. However, since these profits are distributed to the owners of the firm, the price change is equivalent to a redistribution between the workers and the owners. We know that private transfers will offset this redistribution. It is therefore clear that, nets of these transfers, the benefit to owners from adjusting production does not vary with the price of labor.

If prices are irrelevant, then our competitive pricing assumption is plainly inessential. Even the assumption of price-taking behavior becomes vacuuous, since one can change the price for any given transaction without effect. It is therefore not surprising that one can also introduce market power without altering our central result.

Suppose in addition to a non-monopolized consumption good, c, there is also a monopolized consumption good, $x$. The monopolist's price will, of course, be indeterminant, at least within some range. He will exercise his market power by deciding who will consume $x$, and in what amounts. We can thing of the monopolist as making operative tranfers of $x$ to others (the recipients of $x$ may in turn pass some of it on). At the same time, there will be a network of operative transfers in c. Redistributions of $c(x)$ between people who are operatively 
linked in $c(x)$ will be irrelevant. If the linkage hypothesis is satisfied for $c$, then our central result applies with respect to redistributions of $c$. One may even condition such redistributions on transfers of $x$ (i.e., tax the exercise of market power) without effect. Thus, if government fiscal policy entails redistribution of units of account (dollars), the relevant question is whether the linkage hypothesis is satisfied for units of account. However, even if it is satisfied, market power will still matter--changing the identity of the monopolist will necessarily alter the pattern of operative linkages in $\mathbf{x}$ (certainly, the original monopolist will be driven to comers), and will therefore have real allocative effects.

By now, it should be clear that other restrictive features of the model are not central to our analysis. It is, for example, relatively easy to disaggregate consumption, capital, and labor. One can then establish that excise taxes and various partial factor taxes are irrelevant. One may also dispense with the assumption of constant returns-to-scale; we maintained this assumption simply to avoid the necessity of accounting for distributed profits. Perhaps the most important restrictions concern uncertainty and information. Our model describes a deterministic world in which all individuals are perfectly informed. For the most part, we believe that these restrictions are also inessential.

First, suppose we introduce uncertainty concerning length of life, outputs, wages, or gross returns. This would have no effect on our analysis whatsoever. One could simply view nature as a "player," who 
selects current values of these variables according to some random scheme. One would then include nature's choices in the description of a t-history, and proceed as before. Insurance effects, such as those described in Barsky, Mankiw, and Zeldes [1984], would not materialize, since interpersonal transfers would neutralize government redistributive policies for each realization.

Similar remarks apply to uncertainty concerning future government policy. Even if the government randomizes its actions, individuals may condition transfers on policy realizations. Thus, each realization induces a game which is strategically equivalent to the "no policy" game with perturbed corner constraints. Clearly, randomization between equivalent games changes nothing of substance.

Next, suppose individuals have incomplete information about each other's preferences. Consider, for example, a transfer from individual $A$ to individual $C$, where $A$ and $C$ are indirectly linked through $B$. If $C$ is uncertain of $\mathrm{B}^{\prime} \mathrm{s}$ preference, one might think that he would be reluctant to transfer the entire windfall to $B$, since he does not know whether $B$ will choose to pass it on to A, thereby completing the offset. However, this reasoning is faulty. As long as B and A are operatively linked, C need not know B's preferences. Certainly, asymmetric information will affect the nature of equilibrium, but this was also true in the absence of the transfer policy. For the same reasons as before, the policy itself does not alter the strategic environment, except to perturb constraints.

A somewhat more subtle issue concerns information about operative 
linkages. The chains which connect different individuals may be complex; indeed, two individuals may not know how they are connected. Yet it is not clear that this knowledge is at all essential. As long as individuals correctly perceive the effects of their own actions on payoffs, it does not matter if they understand the process which generates these payoffs. Thus, if we prescribe equilibrium actions which offset the effects of some transfer policy, individuals will be willing to abide by these prescriptions. However, this sidesteps a deep and difficult question: how do individuals arrive at the new prescriptions? This issue is completely analogous to the observation that if no single agent knows the "big picture" and coordinates actions, there is no guarantee that an economy will reach a standard competitive equilibrium. To resolve this issue, we would require a theory of how agents achieve equilibria; unfortunately, this important problem is poorly understood. One could envision an iterative process, wherein each individual would reactively adjust his transfers, with the property that stationary points correspond to equilibria. To the extent individuals acknowledge the irrelevance of fiscal policy, the process of adjustment following a policy change might actually be very simple: all agents hold real activities (consumption, production) fixed, and allow transfers to absorb all residual resources. Finally, if one is unpersuaded by these arguments and unwilling to dogmatically accept the implications of equilibrium theory, then one must also regard the dynastic model with considerable skepticism. As we argue in Section 5 , the introduction of myopic concerning patterns of linkages might well 
profoundly alter the implications of dynasticism.

These waters become still murkier if one allows for uncertainty concerning future linkages (e.g., those arising from marriages formed after some individual's death). However, we argue in Section 4 that the linkage hypothesis is likely to be satisfied for small T--one need only use links spanning a few generations, so that most of these links might well be known at the relevant point in time. Even when this is not the case, one can show that the central result continues to hold as long as, for each pair of individuals, one can devise an algorithm which describes transfers as a function of realized linkages (e.g., marriages), and which connects this pair with probability one. Given the wide variety of known links available at each point in time, this condition does not seem very demanding. Of course, the process by which agents achieve such an equilibrium is again problematic.

Finally, suppose that individuals cannot observe some set of actions taken by others. Asymmetric information of this sort may interfere with the neutralization of distortionary taxes. In the proof of our central result, we transformed variables differently for subgames differentiated according to prior choices of taxed activities. For this to be valid, players with transformed actions must be able to distinguish between these subgames; that is, they must be able to observe taxed activities. While this requirement is quite demanding, it may be stronger than is necessary; in some environments, the ability to observe a summary statistic, such as government revenue, may suffice. In any case, these issues do not bear on the neutrality of arbitrary 
lump sum redistributions. Indeed, this weaker form of neutrality does not even require individuals to observe each other's transfers. $15 /$

\section{Interfamily Linkages}

The linkage hypothesis may appear excessively demanding. After all, Barro assumes only that individuals are linked through operative transfers with their children, while our results require interlinkage of the entire population. However, we contend that Barro's hypothesis alone virtually guarantees that our apparently stronger assumption will be satisfied. Our argument makes explicit reference to the biological structure of families.

For illustrative purposes, suppose that all individuals marry, that each marriage produces two children, and that parents are operatively linked to their children. Then, ignoring redundancies, $16 /$ every individual is indirectly linked through common descendents in the next $G$ generations to

$$
\phi(G)=\sum_{i=1}^{G-1} 2^{2 i-1}
$$

members of its own generation. If we assume (as seems natural) that spouses are operatively linked to each other, then one fewer generation is required to establish the same links. Accordingly, to appreciate the importance of links spanning two, three, and four generations, we note that for $G=2,3$, and $4, \phi(G)$ is 2,10 , and 42 , respectively. This, however, is only the "tip of the iceburg." Once we have established that one household is connected to another of same 
generation, we may extend the chain further by moving up and down the family tree as many times as desired. Thus, operative linkages form complex networks, perhaps interconnecting large segments of the population. Indeed, if each couple is connected to ten others (through grandchildren), then the probability of finding a "cycle" (a set of interconnected individuals who are isolated from the rest of the population) seems quite small.

It is possible to formalize this intuition by appealing to existing results concerning the theory of random graphs. This requires some simple preliminaries. A random graph $\Gamma_{n, N}$ is an object consisting of $\mathrm{n}$ nodes and $\mathrm{N}$ edges (lines connecting two nodes), where the edges are selected randomly (all potential edges are equally probable). In our framework, the nodes would represent distinct couples belonging to the same generation. An edge represents a linkage between couples generated by a single movement up and down the tree, spanning at most $G$ generations. Note that we no longer assume every couple is operatively linked to two children, and that all children marry--the number of linkages to a particular couple is random, presumably reflecting differences in the number of children, whether children marry, and whether operative links with children exist. On average, we will assume that couples have two children, so that, as a approximation, $\mathrm{N}=\mathrm{n} \phi(G) / 2.17 /$

Formally, we may now restate our questions as follows: what is the probability that $\Gamma_{n, N}$ is completely connected? What is the expected size of the greatest connected component of $\Gamma_{n, N}$ ? 
Unfortunately, these are fabulously complex combinatoric problems which remain unsolved. There are, however, asymptotic results; for large populations, we may employ asymptotic approximations. Specifically, define

$$
N_{c}=\left[\frac{1}{2} n \log n+c n\right]
$$

where $c$ is an arbitrary fixed real number (so that the number of edges increases slightly faster than linearly in n). Erdos and Renyi [1959] establish that the number of points outside the greatest connected component of $\Gamma_{n, N}$ is distributed in the limit according to Poisson's law, with mean value $e^{-2 c}$.

To apply this result, we consider a sequence of economies indexed by $n$, the number of couples. We fix $c$ at some appropriate level, as discussed below. For each $n$, we select $G$ (the maximum allowable number of generations which a link may span) so that $\mathbb{N}_{c} / n \leqq \phi(G) / 2$ (note that $G$ will increase extraordinarily slowly with $n$ ). 18/ Erdoss and Renyi's theorem then yields lower bounds on the asymptotic probability of complete linkage, and on the expected size of the largest connected component. All that remains is to select an appropriate value for c.

Suppose we wish to obtain asymptotic approximations for a population of 25 million couples (roughly the size of one "generation"), where we consider linkages that span three or fewer generations. Then $\mathrm{n}=25$ million, and $\mathrm{N}=125$ million. This economy corresponds to an element of the sequence formed by setting $c=3.52$. Using Erdos and 
Renyi's result, we see that it would be very unusual to find indirect linkages between all individuals. However, the expected number of individuals outside of the greatest connected component is only 1119. If the asymptotic approximation is accurate, all but a negligable subset of 25 million couples will be indirectly linked through their grandchildren.

Table 1 summarizes these calculations, as well as analogous calculations for $G=2$ and $G=4$. Surprisingly, even if we restrict attention to links which span only two generations (parents and children), on average more than $86 \%$ of the population will be indirectly linked. If we consider links which span as many as four generations, then it is virtually certain that all couples will be indirectly linked. Note that the complexity of these networks actually renders perhaps the majority of interpersonal linkages redundant: typically, two individuals will be connected through several distinct channels. Consequently, if for any reason a family's chain of operative linkages is severed, this does not imply, as in Barro's analysis, that the neutrality results are inapplicable. Lateral connections between families will ordinarily suffice to circumvent isolated breaks in any chain. Thus, the linkage hypothesis is typically satisfied under much weaker conditions than those imposed by Barro, and our results are immune to the well-known criticism that Ricardian equivalence holds only if family chains never break. In addition, other results in the literature on random graphs (c.f., Bollobas [1981]) suggest that typically the chains connecting pairs of individuals are surprisingly 
short, so that each link may be used relatively few times to offset any given policy, as claimed in Section $3 C$.

Finally, we note two important problems which arise concerning our application of graph theoretic results. First, contrary to our assumption, not all links are equally probable. Individuals are most likely to marry others who live in the same geographic areas, and some communities, such as the Amish, are almost entirely self-contained. Intuitively, one would expect this modification to make very little qualitative difference. Consider, for instance, a society with a virtually perfect caste system. Suppose that each caste is internally linked (every member of a caste is linked to every other member). A single "intermarriage" will the serve to link the entire population. of course, in such a society, families might disown the intermarried couple. Even if they did not, in acting as a conduit for all resource flows between the two castes, the couple would undoubtably be driven to corners, which would render their linkages inoperative. However, for the most part, the "intermarriages" which concern us here would not violate social customs, and hence generate severence of financial ties. In addition, the "single intermarriage" case is extreme; we suspect that links between most large population groups are far more common (consider, for example, the frequency of racial intermarriages). Second, contrary to our assumption, links are not distributed independently. Most importantly, once an individual is linked to someone, the probability that he is linked to someone else changes. Our failure to account for this factor is clearly responsible for the 
conclusion that all individuals are linked through chains spanning four generations: the presence of childless individuals renders this conclusion untenable. However, one might well suppose that, ordinarily, once an individual is operatively linked to anyone else, he becomes attached to a much larger network.

In both cases, we may be somewhat more formal about our intuition. Let $A_{n, N}$ be the set of graphs consisting only of one connected subset, and isolated nodes (points which do not support any edge). Erdös and Renyi [1959] demonstrate that the probability of selecting a graph in $A_{n} N_{C}$ goes to one as $n$ goes to infinity. This is true regardless of $c$, so we may select $c$ to reflect either the low probability of intermarriages, or some lower bound on the conditional probability of additional linkages (in each case understating the true extent of operative networks). The result suggests that, in general, anyone who is operatively linked to anyone else will be indirectly linked to everyone, except for those who are completely isolated. We close this section with one final thought. In practice, people are connected through operative transfers not just to children, but also to siblings, nieces, nephews, cousins, charities, political organizations, and so forth. Thus, we strongly suspect that, even accounting for the childless, very few individuals or groups of individuals are truly isolated in the sense discussed here. 
5. Interpretations and Conclusions

What should one make of the rather perplexing conclusions reached in Sections 2 through 4? In particular, several points of interpretation require further discussion. First, what general principles drive our neutrality results? Second, what does this analysis teach us about "real" economics? Third, where do we go from here? We address these questions in subsections $A, B$, and $C$, respectively.

A. Optimality versus Neutrality

At first, one might suspect that our analysis is closely related to other results which are known to hold under somewhat special circumstances. Consider, for example, an economy consisting of a single (as opposed to representative) dynastic family, where family members have dynamically consistent preferences. In this world, every consumer acts as though he is part of a "big happy family", which maximizes a single utility function. Clearly, all lump sum transfers are neutral-the family responds to any such policy by reestablishing its optimum (indeed, this is the popular intuition for Barro's theorem). Furthermore, "distortionary" taxes cannot displace the big happy family from its optimum.

of course, when one abandons the dynamically consistent formulation of family preferences, one cannot immediately apply the same set of arguments. However, there is some reason to believe that the same basic principles may be operative. In particular, Becker [1974] has argued that, as long as family members are linked through an altruist, each 
member acts to maximize family welfare. Although Becker establishes his result in a rather restrictive environment, one might suspect that, in some sense, our analysis contains a generalization of this "Rotten Kid Theorem."

However, this reasoning is simply false, and the conclusions which follow from it invalid. As discussed in Bernheim, Shleifer, and Summers [1985], Becker's "Rotten Kid Theorem" does not hold when one relaxes his restrictive assumptions, so the current analysis cannot be founded upon the "big happy family" view. Accordingly, it is essential to understand that our results concern neutrality, not optimality. Recall Example 2 of Section 2. There we argued that a labor income tax was neutral, since it left 1 's effective wage unaltered. We did not, however, assert that 1 chose his labor supply optimally in the initial equilibrium. Specifically, we did not say that 1's effective wage was w. Rather, he faced some shadow wage, which reflected the effect of his labor supply choices on subsequent transfers. We argued only that this shadow wage was insensitive to tax and transfer policies. This principle is quite general: in equilibrium, chosen actions may well be inefficient, but redistributions contingent upon these choices will not effect behavior. Aside from delimiting the scope of neutrality, this observation also implies that our results have no normative implications. Although all taxes are equivalent to lump sum taxes, lump sum taxation may not be desirable. Since the equilibrium ordinarily entails preexisting distortions (due to intrafamily conflict), the government would want to engage in second-best taxation. However, paradoxically, second-best tax 
instruments are unavailable. The government can introduce countervailing distortions only by conditioning real expenditures on consumer behavior.

\section{B. Policy Implications}

Our analysis calls into serious question the usefulness of the dynastic framework as an analytic tool for studying public policy issues. Unless one is willing to accept untenable conclusions, it is necessary to abandon some premise central to this framework. One must therefore regard any conclusions derived from these premises with considerable skepticism.

Barro's Ricardian equivalence results, which concern the neutrality of public deficits and social security, are probably the best known implications that follow from dynastic assumptions. Yet our criticism also applies to a variety of other studies which adopt Barro's model. For example, Abel [1984] demonstrates that social security may have real effects in a dynastic world by inducing redistributions between families. In light of our analysis, it is clear that, once one adopts dynastic assumptions, distributional questions are ill-posed. Judd [1985] and Chamley [1981] study the welfare effects of capital income taxation in dynastic models. Yet the premises of these models may imply neutralization of the very distortion which they purport to study.

A natural response to our criticism is that one ought to view the dynastic formulation as only an approximation to reality; one should therefore expect properties such as Ricardian equivalence to hold only 
as approximations. Taking the premises of this model literally is simply unfair, and bound to generate some untenable results.

We find this response completely unsatisfactory. It is clear that both the degree and nature of the approximation will matter a great deal. If we agree that taxes, transfers, and prices are not even close to being irrelevant, then we must also agree that in some important, policy-relevant sense the world is not even close to being dynastic. One cannot simply assert that the model holds as a good approximation in one context, but not in another. It is essential to describe the approximation explicitly, so that analysts can identify a new set of assumptions and elucidate their implications.

It may well be that one can modify the dynastic model in a way which addresses our criticism, while preserving central implications such as Ricardian equivalence. The first author is pursuing this possibility in current work with Andrew Abel; but has found the task quite difficult.

Consider an example. One might argue in defense of Ricardian equivalence as follows. Our criticism disparages results which depend on relatively long (although recall our remark in Section 4), indirect linkages. Individuals may, however, be myopic about effects which work their way through complex, poorly understood networks, while being perfectly rational about short, direct chains. Thus, public deficits redeemed within a few generations may well be approximately irrelevant, while policies which concern distribution within a generation are not. Yet a bit of reflection suggests that matters are not nearly so 
simple. To illustrate, consider a world in which each couple has two children, and all children marry. Suppose for convenience that the interest rate is zero. The government undertakes a pure Ricardian exercise, reducing taxes by $\$ 10$ on each couple today, and increasing taxes by $\$ 10$ on each couple belonging to the next generation. What are the effects of this policy?

Suppose initially that individuals understand the policy, but are completely myopic about the behavior of others to whom they are only indirectly linked. An arbitrary couple (A) belonging to the current generation will then perceive that the wealth of its family has fallen by $\$ 10-$-while it receives $\$ 10$, each child loses $\$ 10$. Consequently, the deficit policy will have substantial real effects.

For Ricardian equivalence to hold, couple A must understand that it is indirectly linked to two other sets of parents ( $B$ and $C$ ). Even if A understands this, it must be fairly sophisticated about coordinating actions with the other parents. There are an infinite number of ways to offset this policy--each couple could give $\$ 5$ to each child, $\$ 10$ to one child and nothing to the other, or, more generally, $\$ \mathrm{x}$ to one child and $\$ 10-x$ to the other. Further, when $A$ worries about coordinating actions with $B$ and $C$, it must consider the fact that $B$ and C face similar problems with two other couples, $D$ and $E$. If $B$ fails to coordinate properly with $D$, then $B$ will in general not wish to join $A$ in offsetting the policy for their married children, as described above. Effectively, A must believe that everyone is coordinating actions through the entire web of linkages, and that this is common knowledge. 
Thus, when families are interlinked, Ricardian equivalence does not appear to demand a lower level of rationality than do our results.

\section{Where Next?}

Our arguments depend most heavily upon several central

assumptions. First, we assume that operative linkages are quite common. Second, we assume that individuals care only about the consequences of giving, and not directly about the amount given. To establish the irrelevance of all fiscal policies and prices, we must also assume that actions are publicly observable. If one relaxes this last assumption and supposes instead that capital markets are perfect, it is then possible to demonstrate that all lump sum redistributions are irrelevant. In order to conduct constructive policy analyses, one must modify one or more of these basic premises. We consider them in reverse order.

The last two assumptions are certainly objectionable on empirical grounds. However, this does not fully account for our skepticism concerning the model's implications. Suppose hypothetically that the government adopted and effectively enforced (through enormous penalties) a new law requiring public disclosure of all private financial decisions. We would not expect fiscal policy and prices to become irrelevant as a consequence. We conclude that an important source of our disbelief must lie elsewhere.

The second assumption might fail for several reasons. Generosity may be inherently fulfilling. Alternatively, individuals might be myopic with respect to the actions of their heirs, and simply take the 
size of transfers as a proxy for well-being. Both views are somewhat appealing, but neither leads to a satisfactory theory of transfers. For example, it is difficult to know why an individual would care about the magnitude of his transfer if it truly did not affect any real outcome. In both cases, the specification of the transfer motive is necessarily ad hoc.

Violations of the first assumption fall into two categories: either a large number of people fail to make positive transfers, or corners matter despite the fact that transfers are positive. Many commentators have indeed claimed that corner constraints bind for most individuals. Barro [1984] offers a theoretical reason for expecting this outcome, but does not elucidate implications for policy. Our analysis suggests a somewhat different reason, which raises some intriguing possibilities.

To illustrate, consider a world in which there are three successive generations $(t=1,2,3)$, each consisting of $N$ households. For purposes of interpretation, one should think of each household as a married couple. Each member of generation $t=1,2$ has two children, but, of course, children are shared (a child-household is formed by the marriage of two individuals who come from two different parent households). Suppose that the children of the $i-$ th household in generation 1 belong to the $m(i)$-th and $f(i)$-th households in generation 2 (where these indices are assigned so that everyone in generation 2 has two forebearers in generation 1). Further suppose that the children of the $i-t h$ household in generation 2 belong to the $i-t h$ and $i+1-$ th 
households in generation 3 (with the exception that N's children belong to the $N$-th and first households). We select this stylized pattern of linkages in order to guarantee that there is a chain that interconnects the entire population.

We will assume that all households are identical within generations. The utility of household $i$ in generation $t$ is given by

$$
u_{i}^{t}= \begin{cases}u\left(c_{i}^{1}\right)+k\left(u_{f(i)}^{2}+u_{m(i)}^{2}\right) & t=1 \\ u\left(c_{i}^{2}\right)+k\left(u_{i}^{3}+u_{i+1}^{3}\right) & t=2 \\ u\left(c_{i}^{3}\right) & t=3 .\end{cases}
$$

This individual is endowed with initial wealth, $\mathrm{w}^{\mathrm{t}}$.

Behavior unfolds as follows. First, each member of generation 1 chooses its own consumption, and transfers to its children. Next, each member of generation 2 does the same. Finally, members of generation 3 consumer their endowments, plus all transfers received.

Suppose that along some symmetric subgame perfect Nash equilibrium path, all members of generation 2 make operative transfers to their children.19/ The analysis of Section 3 then establishes that the consumption of any household in either generation 2 or 3 depends only upon the total resources available to all members of those generations. If $\mathrm{N}$ is large, then the marginal propensity to consume from wealth for any given individual must be close to zero (this point is analogous to Sugden's [1982] observation concerning the provision of charity). Thus, each member of generation 1 knows that his gifts will 
have a negligible impact upon the consumption of his descendents. In contrast, gifts involve a non-negligible sacrifice of his own consumption. Thus, under relatively weak conditions, no member of generation 1 will make an operative transfer.

The main point raised by this discussion is that in large populations where preferences are dynastic and decisions are sequential, large numbers of individuals must end up at corners. In addition, the particular model considered here produces endogenous cycles: one generation acts altruistically, making transfers to its children, while the next generation, despite being identical to the first, acts selfishly (this remains true as one adds generations). While we do not seriously propose this particular pattern as descriptive of the real world, our analysis does suggest that endogenous behavior may well give rise to patterns of operative linkages that do not generate standard dynastic results, such as Ricardian equivalence.

While there are both empirical and theoretical reasons for doubting that most individuals make positive transfers, we are unable to fully attribute our disbelief to this assumption. We suspect that, the thrill of victory aside, most individuals would prefer winning $\$ 1,000$ in a lottery, to learning that one of their siblings has won $\$ 1,000$, despite the expectation of future transfers from the parent. Yet dynasticism implies that one should be indifferent.

We are therefore led to reexamine the other aspect of our first assumption: corners matter, even though they do not bind, in the traditional sense. So far as we know, the only fully elaborated 
theories which are compatible with this view envision transfers as a means of facilitating exchange within families (see, for example, Kotlikoff and Spivak [1981], and Bernheim, Shleifer, and Summers [1985]). Accordingly, we believe that subsequent policy analyses should consider more carefully the implications of non-standard alternatives to the dynastic transfer motive. 
Footnotes

1/ Overlapping generations models are not only generally less tractable, but also often give rise to equilibria with undesirable properties. Specifically, equilibria in overlapping generations models may fail to be either efficient or locally unique (see Balasko and Shell [1980] and Kehoe and Levine [1985]). Failure of local uniqueness is particularly troubling in any exercise involving comparative statics or dynamics. Thus, Judd [1985] unabashedly attributes his adoption of the dynastic framework to analytic convenience. Unfortunately, this advantage may be illusory. In a recent paper, Gale [1985] has pointed out that, while Barro's dynastic solution is an equilibrium for the model which he considers, this model also generally gives rise to a continuum of subgame perfect intergenerational equilibria (see Selten [1965, 1975]), many of which are inefficient. By adopting dynastic assumptions, one therefore does not necessarily succeed in avoiding the problems which arise in the standard overlapping generations framework.

2) Barro [1974, p. 1097] explains that "current generations act effectively as though they were infinite-lived when they are connected to future generations by a chain of operative intergenerational transfers." Subsequent papers reinforced the notion that Ricardian equivalence is somehow tied to the dynamically consistent formulation of family preferences; see, for example, Buiter and Carmichael's [1984] dispute with Burbidge $[1983,1984]$.

3/ Equilibria are quite generally inefficient in models with interlocking families. One important reason has been emphasized by Nerlove, Razin, and Sadka [1984]: when unrelated individuals share a common descendent, the consumption of that descendent is a public good.

4/ In fact, one can think of agent 3 as a public project financed by voluntary contributions, in which case the analysis of Bergstrom, Blume and Varian [1984] establishes the neutrality result. We are aware that Lawrence Kotlikoff also derived this result independently. These authors did not, however, note the strategic equivalence of the pre- and post-transfer games (which makes the result substantially more general), nor did they discover the neutrality of so-called "distortionary" taxes (and the implications, discussed in Section 5, for the role of prices in resource allocation). In addition, the framework employed by Bergstrom, Blume, and Varian is substantially more restrictive than the general model considered in Section 3 (their neutrality result was established for networks of interpersonal linkages with a very specific structure). We also note that Carmichael [1982] 
had previously recognized that the key to Barro's theorem concerned the preservation of opportunity sets, rather than the specification of altruism.

5/ In this example, equilibria are generally inefficient due to the public good problem noted in Footnote 2.

6/ Two games are strategically equivalent if they have the same extensive forms.

If Our central result depends critically on the assumption that strategically equivalent games yield equivalent equilibria. Essentially, this implies that we can think entirely in terms of abstract actions, ignoring the primitive actions to which these actually correspond. Yet in many situations, primitive actions may play a role in determining behavior. The most obvious role arises when the game yields multiple equilibria--players may gravitate toward equilibria in which their choices are close to certain focal alternatives (e.g., zero transfers, or transfers prior to the policy perturbation). It is, however, difficult to see how this possibility could invalidate our result wi thout simultaneously rendering the dynastic framework inapplicable.

8/ Indeed, the purpose of many refinements is to rule out equilibria which are sensitive to perturbations in either the environment or in the rules governing behavior (see Fudenberg, Kreps and Levine [1986]).

9/ Of course, if 2 must hurt himself to carry out this threat, 1 might choose to call 2's "bluff"--accordingly, these equilibria are not subgame perfect.

10/ Details of such calculations are available from the authors upon request. The reader may also wish to consult Bernheim (1986).

11 One could also allow consumers to lock in transfers for a number of years, including transfers to unborn generations. This would change nothing of substance.

12 Note that we do not allow $z_{i}^{t}$ to depend upon current (period $t$ ) choices. Effectively, the government collects tax revenues at the "end" of each time period (in the last period of life, revenues must be collected from the individual's estate, or equivalently, from his heirs). This aspect of our model is an artifact of discrete time--we model the government policy in this way so that private and public transfers are on an equal footing (within a single period, both may be conditioned on the same behavior). 
13/ There is, for example, a growing literature which analyses models in which each generation cares about its own consumption, and the consumption of its successor (see, e.g., Arrow [1973], Dasgupta [1974a,b], Kohlberg [1976], Lane and Mitra [1981], Bernheim and Ray $[1983,1986]$, and Leininger [1986]). Bernheim and Ray [1983] and Leininger [1986] established existence of Nash equilibria in the class of continuous consumption functions which are upper semicontinuous from the left, with limits from the right. Despite the simplicity of these models, there are no known conditions which guarantee that these functions will be either continuous or concave in any reasonably general set of environments. In fact, Kohlberg [1976] has shown that Nash equilibria in continuously differentiable strategies do not generally exist.

14/ The reader may verify this through a slight modification of the argument used in Section 3C.

15/ In example 1, we have assumed that 1 and 2 select transfers simultaneously. This is equivalent to letting 1 choose first, and assuming that 2 then selects a transfer without having observed 1 's choice.

16/ e.g. the possibility that siblings have different in-laws. For large populations and small values of $G$, this is presumably an excellent approximation.

17/ Each edge represents a link for two couples; hence we divide the number of links by two to obtain the number of edges.

18/ In particular, for the values of $c$ considered here, it is not necessary to consider linkages which span more than four generations until the population size exceeds $10^{15}$.

19/ One can derive relatively weak conditions under which this occurs. 


\section{References}

Abel, A. [1984], "Capital Accumulation and Uncertain Lifetimes with Adverse Selection," mimeograph, Harvard University.

Arrow, K. [1973], "Rawls' Principle of Just Saving," Swedish Journal of Economics, pp. 323-335.

Balasko, Y. and K. Shell [1980], "The Overlapping Generations Model, I: The Case of Pure Exchange without Money," Journal of Economic Theory 23, 281-306.

Barro, R. [1974], "Are Government Bonds Net Wealth?" Journal of Political Economy 82, pp. 1095-1117.

Barro, R. [1976], "Reply to Feldstein and Buchanan," Journal of Political Economy 84, pp. 343-350.

Barro, R. [1984], "On Patterns of Interpersonal Transfers," mimeograph, University of Chicago.

Barsky, R., G. Mankiw, and S. Zeldes [1984], "Ricardian Consumers with Keynesian Propensities," NBER Working Paper No. 1400.

Becker, G. [1974], "A Theory of Social Interactions," Journal of Political Economy 82, pp. 1064-1093.

Bergstrom, T., L. Blume, and H. Varian [1984], "On The Private Provision of Public Goods," mimeograph, University of Michigan.

Bernheim, B. D. [1986], "On the Voluntary and Involuntary Provision of Public Goods," American Economic Review, forthcoming.

Bernheim, B.D. and D. Ray [1986], "Economic Growth with Intergenerational Altruism," Review of Economic Studies, forthcoming.

Bernheim, B.D. and D. Ray [1983], "Altruistic Growth Economies I: Existence of Bequest Equilibria," Institute for Mathematical Studies in the Social Sciences, The Economics Series, Technical Report No. 419, Department of Economics, Stanford University, Stanford, California.

Bernheim, B.D., A. Shleifer and L. Summers [1985], "The Strategic Bequest Motive," Journal of Political Economy 93, 1045-1076.

Bollabas, B. [1981], "The Diameter of Random Graphs," Transactions of the American Mathematical Society, 267, No. 1. 
Buchanan, J. [1976], "Barro on the Ricardian Equivalence Theorem," Journal of Political Economy 84, 337-342.

Buiter, W. and J. Carmichael [1984], "Government Debt: Comment," American Economic Review 74, pp. 762-765.

Burbidge, J. [1983], "Government Debt in an Overlapping-Generations Model with Bequests and Gifts," American Economic Review, 73, pp. 222-227.

Burbidge, J. [1984], "Government Debt: Reply," American Economic Review 74, pp. 766-767.

Carmichael, J. [1982], "On Barro's Theorem of Debt Neutrality: The Irrelevance of Net Wealth," American Economic Review 72, pp. $202-213$.

Chamley, C. [1981], "The Welfare Cost of Capital Taxation in a Growing Economy," Journal of Political Economy 89, pp. 468-496.

Dasgupta, P. [1974a], "On Some Problems Arising from Professor Rawls' Conception of Distributive Justive," Theory and Decision 4, pp. 325-344.

Dasgupta, P. [1974b], "On some Alternative Criteria for Justice between Generations," Journal of Public Economics 3, pp. 405-423.

Diamond, P. [1965], "National Debt in a Neoclassical Growth Model," American Economic Review 55, pp. 1126-1150.

Drazen, A. [1979], "Government Debt, Human Capital, and Bequests in a Life Cycle Model," Journal of Political Economy 86, pp. 505-516.

Erdos, P. and A. Renyi [1959], "On Random Graphs I," Publications Mathematicae 6, pp. 290-297.

Feldstein, M. [1976], "Perceived Wealth in Bonds and Social Security: A Comment," Journal of Political Economy 84, pp. 331-336.

Fudenberg, D., D. Kreps, and D. Levine [1986], "On the Robustness of Equilibrium Refinemenst," Institute for Mathematical Studies in the Social Sciences, The Economics Series, Technical Report

No. 489, Department of Economics, Stanford University, Stanford, California.

Gale, D. [1985], "The Strategic Analysis of Bequest Behavior: A Critique of the Ricardian Equivalence Theorem," mimeograph, University of Pennsylvania. 
Judd, K. [1985], "The Welfare Cost of Factor Taxation in a Perfect Foresight Model," mimeograph, Northwestern University.

Kohlberg, E. [1976], "A Model of Economic Growth with Altruism Between Generations," Journal of Economic Theory 13, pp. 1-13.

Kotlikoff, L. and A. Spivak [1981], "The Family as an Incomplete Annuities Market," Journal of Political Economy 89, pp. 372-391.

Lane, J. and T, Mitra [1981], "On Nash Equilibrium Programs of Capital Accumulation under Altruistic Preferences," International Economic Review 22, pp. 309-331.

Leininger, W. [1983], "The Existence of Nash Equilibria in a Model of Growth with Altruism Between Generations," mimeograph, University of Bonn.

Kehoe, T. and D. Levine [1985], "Comparative Statics and Perfect Foresight in Infinite Horizon Economies," Econometrica 53, pp. 433-454.

Menchik, P. [1980], "Primogeniture, Equal Sharing, and the US Distribution of Wealth," Quarterly Journal of Economics 94; pp. 279-316.

Nerlove, M., A. Razin and E. Sadka [1984], "Bequests and the Size of Population When Population is Endogenous," Journal of Political Economy 92, pp. 527-531.

Pollak, R. [1968], "Consistent Planning," Review of Economic Studies 35.

Selten, R. [1965], "Spieltheoretische Behandlungeines 0ligopolmodells mit Nachfragetsagheit," Zeitschrift fur die Gesamte Straatiswissenschaft 121, pp. 301-324.

Selten, R. [1975], "Reexamination of the Perfectness Concept for Equilibrium Points in Extensive Games," International Journal of Game Theory 4, pp. 25-55.

Shenshinki, E. and Y. Weiss [1981], "Uncertainty and Optimal Social Security Systems," Quarterly Journal of Economics 96, pp. 189-206.

Strotz, R. [1956], "Myopia and Inconsistency in Dynamic Utility Maximization," Review of Economic Studies 23, pp. 165-180.

Sugden, R. [1982], "On the Economics of Philanthropy," Economic Journal 92, pp. $341-350$. 
Tobin, J. and W. Buiter [1980], "Fiscal and Monetary Policies, Capital Formation, and Economic Activity," in The Government and Capital Formation, ed., George M. von Furstenberg, Cambridge, MA.: Ballinger Press. 


$$
-68-
$$

Table 1

Asymptotic Approximations for the Distribution of Linked Subsets

\begin{tabular}{|c|c|c|c|c|}
\hline G & $\mathbf{N}$ & c & $\begin{array}{l}\text { Probability of } \\
\text { Complete Linkage }\end{array}$ & $\begin{array}{c}\text { Expected Fraction of } \\
\text { Population in Largest } \\
\text { Linked Subset }\end{array}$ \\
\hline 2 & $\mathrm{n}$ & $-7 \cdot 52$ & 0.00 & 0.86660 \\
\hline 3 & $5 n$ & -3.52 & 0.00 & 0.99996 \\
\hline 4 & $21 n$ & 12.48 & 1.00 & 1.00000 \\
\hline
\end{tabular}


Figure 1: Schematic Representation of Example 2

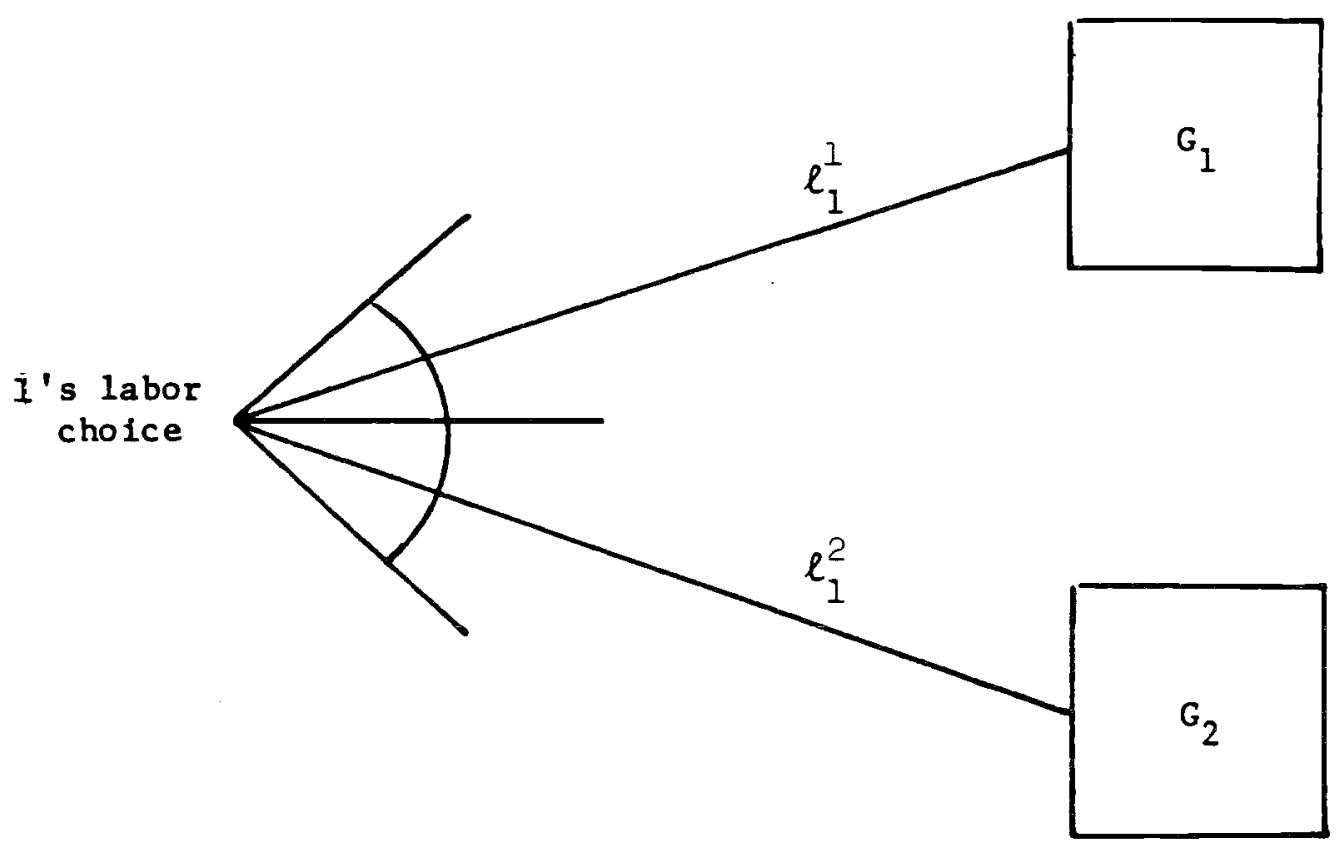

Figure 1(a): Policy z

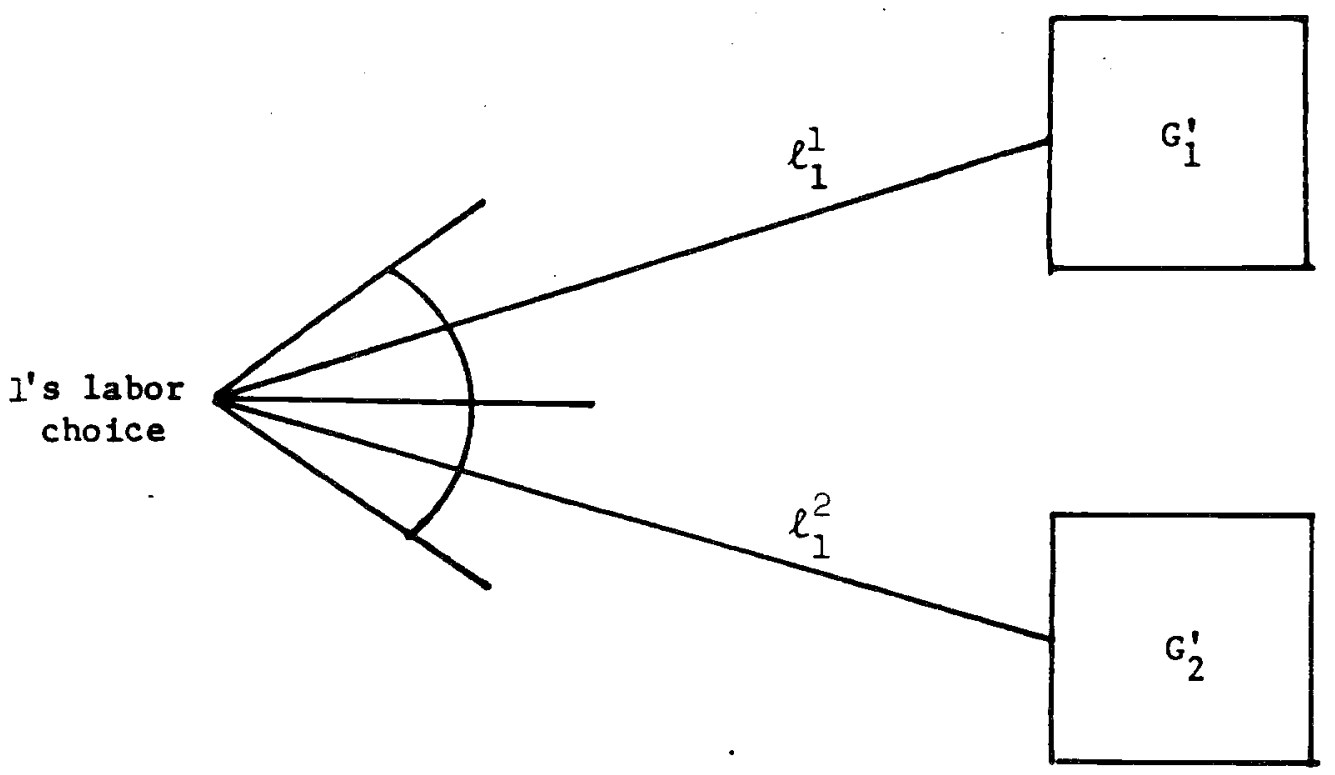

Figure 1(b): Policy $z^{\prime}$ 